Research Article

\title{
Structural Optimization Design of Ship Lock Heads on Soft Soil considering Time-Varying Effects of the Structure and Foundation
}

\author{
Jiawei Bai $(\mathbb{D}$, Chao Su $(\mathbb{D}$, Heng Zhang $(\mathbb{D}$, and Shaopei Hu \\ College of Water Conservancy and Hydropower Engineering, Hohai University, Nanjing 210098, China \\ Correspondence should be addressed to Chao Su; csu_hhu@126.com
}

Received 11 January 2021; Revised 1 March 2021; Accepted 30 March 2021; Published 13 April 2021

Academic Editor: Hao Gao

Copyright ( 2021 Jiawei Bai et al. This is an open access article distributed under the Creative Commons Attribution License, which permits unrestricted use, distribution, and reproduction in any medium, provided the original work is properly cited.

\begin{abstract}
Over time, the uneven settlements of the structure and foundation are prominent in constructing ship lock heads on soft soil. These deformations endanger the safety of ship lock heads during construction. This research aimed to establish the ship lock head's structural optimization procedure on soft soil, considering the time-varying effects of the structure and foundation. By comprehensively considering the linear viscoelastic creep of concrete and the elastoplastic consolidation characteristic of soft soil, a perfect time-dependent analysis method for the lock head on soft soil was proposed. Furthermore, a hybrid particle swarm optimization, enhanced whale optimization, and differential evolution (PSO-EWOA-DE) algorithm was proposed to optimize thirty-four design variables of a lock head. With the minimal volume of the lock head as the optimization objective, the finite element model was established. In the optimization process, three types of constraints were evaluated. The result showed that the optimized design could reduce $10.45 \%$ of structure volume. Through comparing and analysing the maximum principle stresses and vertical displacements of the lock head before and after optimization, some conclusions were drawn. The optimization procedure proposed in this paper provides a new perspective for the structural optimization of hydraulic structures on soft soil.
\end{abstract}

\section{Introduction}

As one of the most critical navigation structures, ship locks use hydraulic power to lift ships through dams built on natural or canalized rivers [1]. Ship locks are mostly built on soft-soil sites in coastal areas. Soft soil has the characteristics of low shear strength [2], high compressibility, and a large settlement. In practical engineering, building crashes caused by uneven foundation settlement are not uncommon. Therefore, the accurate calculation of foundation settlement is an issue of particular concern to designers and contractors. The lock head is a complicated structure with water-retaining and ship passing functions, and it separates the lock chamber from the approach channel. In the past few years, some progress in the lock head's structural optimization has been achieved. Based on the material's elastic assumption, Su et al. [3] optimized the lock head volume using the finite element method (FEM) to effectively use the concrete material. Subsequently, considering the impact of concrete creep on the structure during the construction period, Su and Bai [4] optimized the lock head on the rock foundation. Under the lock head's gravity, the soft foundation will experience consolidation settlement. Therefore, the structural optimization of the lock head should consider the time-varying characteristics of the structure and foundation.

Many algorithms have been used in structural engineering optimization tasks over the past few decades, from gradient-based algorithms to nongradient probabilisticbased algorithms [5]. The latter category contains many algorithms that imitate natural phenomena, such as ant colony algorithm [6] and particle swarm optimization (PSO) [7], among others. The gradient-based algorithms have difficulties in dealing with inequality constraints [8]. 
Evolutionary algorithms (EAs) are the most successful optimization techniques [9]. The PSO is a variant of EA based on bird flocking [10]. It was proposed based on birds' cardinal rules: the simultaneous gathering of a large number of birds, often changing direction suddenly, dispersing, and rearranging [11]. The PSO has few parameters and a fast convergence rate, and it is easy to implement [12]. Nowadays, the PSO has achieved encouraging results in structural design applications. Fourie and Groenwold solved the shape [11] and topology [13] optimization problems using the PSO. Venter and SobieszczanskiSobieski [14] applied the PSO to the multidisciplinary optimization of transport aircraft wings. The whale optimization algorithm (WOA) is a novel population-based metaheuristic optimization algorithm, originally developed by Mirjalili and Lewis [15]. Some important parameters of the WOA are self-tuning along the evolutionary process, and the WOA also needs few parameters to set [16]. It mimics the hunting behaviour of humpback whales [17]. The main hunting steps are included in this method: searching for the prey, encircling the prey, and attacking the prey [18]. Compared with other metaheuristic algorithms, the whale algorithm can obtain very competitive results in solving various practical problems [19] such as determining the optimal distributed generator size [20], selecting features [21], and clustering the data [22]. Kaveh and Ilchi Ghazaan [23] proposed the enhanced whale optimization algorithm (EWOA) to improve the solution's accuracy. Compared with WOA, EWOA has fewer parameters and conditional statements [24]. The difference evolution (DE) algorithm is a robust population-based global optimization algorithm [25]. It performs effectively in solving constrained parameter optimization problems [8]. The main DE steps include mutation, crossover, and selection [26]. The DE has a reliable search capability [27]. Recently, to improve optimization results, some optimization methods that hybridize multiple evolutionary techniques have been proposed [26]. Zhou et al. applied the PSO-DE algorithm to optimize the operation of heated oil pipelines [28].

The creep phenomenon was discovered by Hatt in 1907 [29]. For early-age concrete, thermal stresses are greatly affected by creep deformations [30]. Concrete creep is the strain that changes with time caused by continuous stress [31]. It will influence the serviceability of the concrete structure [32]. Many experiments have been performed to collect short-term and long-term creep data of concrete [33]. Subsequently, a large number of creep prediction methods were proposed based on experimental results [34], such as the GL2000 model [35], the BP model [36], and the ACI 209R-92 model [37]. Bažant and Xi [38] believed that the Kelvin chain could accurately describe the linear viscoelastic creep model, and they used the Dirichlet series to represent the creep compliance function. Zhu [39] proposed a series of implicit recursive equations and provided a large number of calculation parameters suitable for hydraulic concrete structures. Wang and Liu [40] verified this method's correctness by comparing the calculation results of the Gongzui gravity dam's thermal creep stress with theoretical solutions.

Consolidation is the time-settlement behaviour of clay. The clay instantaneously settles under the load's action without drainage, and then the excess pore pressure gradually dissipates [41]. Terzaghi first proposed the one-dimensional consolidation theory in 1925 [42]. Biot further studied the coupling effect of three-dimensional deformation materials and pore fluid pressure and developed a more general consolidation theory [43]. Sandu and Wilson presented a solution for Biot's consolidation theory based on the FEM [44]. Since local yielding occurs when the soil is loaded, Small et al. formulated the elastoplastic consolidation equations on the basis of incremental solution strategies [41]. The modified Cam-clay model (MCC) is a critical-state model most widely used to predict soft soils' behaviour [45]. It only requires a few parameters which are convenient for laboratory determination [46]. For soft soils, Jain deduced the elastoplastic consolidation equations incorporating MCC [47]. However, few optimization studies have considered the consolidation characteristics of soft foundations.

In this article, a structural optimization method for ship lock heads on soft soil was established considering the time-varying effects of the structure and foundation. Meanwhile, by comprehensively considering the linear viscoelastic creep of concrete and the elastoplastic consolidation characteristic of soft soil, a perfect time-dependent analysis method for the lock head on soft soil was proposed. With the minimal volume of the lock head as the optimization objective, a hybrid particle swarm optimization, enhanced whale optimization, and differential evolution (PSO-EWOA-DE) algorithm was applied to obtain the optimal shape. A comparison of the results obtained by the PSO-EWOA-DE algorithm with those of PSO, WOA, DE, EWOA, and PSO-DE methods revealed that the proposed algorithm was more effective in the structural optimization of a ship lock head and had a faster convergence rate. The remainder of this paper is structured as follows. Section 2 deliberates governing equations of concrete thermal creep stress and soil consolidation theory. Section 3 describes the structural optimization problem in detail. The PSO, WOA, EWOA, and DE algorithms are briefly introduced in Section 4. Section 5 introduces the PSO-EWOA-DE algorithm and its main implementation details in structural optimization. Section 6 presents an engineering example of a ship lock head. Finally, some conclusions are given in Section 7.

\section{Governing Equations}

2.1. Thermal Creep Stress of Mass Concrete. For mass concrete structures, the compliance function is expressed as follows [48]:

$$
J\left(t, t^{\prime}\right)=\frac{1}{E(\tau)}+C\left(t, t^{\prime}\right)
$$


The creep compliance function can be written in the following Dirichlet series form [39]:

$$
C\left(t, t^{\prime}\right)=\sum_{i=1}^{N} \psi_{i}\left(t^{\prime}\right)\left\{1-\exp \left[-\alpha_{i}\left(t-t^{\prime}\right)\right]\right\} .
$$

In addition,

$$
\begin{aligned}
& E\left(t^{\prime}\right)=E_{0}\left[1-\exp \left(r t^{\prime \lambda}\right)\right], \\
& \psi_{i}\left(t^{\prime}\right)=f_{i}+g_{i} t^{\prime p_{i}}
\end{aligned}
$$

where $t$ is the age of concrete, $t^{\prime}$ is the loading age in days, $N$ is the number of Kelvin chains, $E\left(t^{\prime}\right)$ is the instantaneous elastic modulus, $E_{0}$ is the ultimate elastic modulus, and $\alpha_{i}, r$, $\lambda, f_{i}, g_{i}$, and $p_{i}$ are parameters obtained by creep experiments.

For viscoelastic materials, stress increment in $3 \mathrm{D}$ can be calculated by the following equation [39]:

$$
\left\{\Delta \sigma_{n}\right\}=\left[D_{n}\right]\left(\left\{\Delta \varepsilon_{n}\right\}-\left\{\eta_{n}\right\}-\left\{\Delta \varepsilon_{n}^{T}\right\}\right),
$$

where

$$
\left[D_{n}\right]=\frac{1}{J\left(t, t^{\prime}\right)}[Q]^{-1}
$$

$$
\begin{gathered}
\left\{\eta_{n}\right\}=\sum_{i=1}^{N}\left[1-\exp \left(-r \Delta t_{n}^{\prime}\right)\right]\left\{\omega_{\text {in }}\right\}, \\
\left\{\Delta \boldsymbol{\varepsilon}_{n}^{T}\right\}=\gamma\{\Delta T\}\left[\begin{array}{llllll}
1 & 1 & 1 & 0 & 0 & 0
\end{array}\right]^{T} .
\end{gathered}
$$

In these equations, $\left\{\Delta \sigma_{n}\right\}$ is the stress increment, $\left\{\Delta \varepsilon_{n}\right\}$ is the total strain increment, $\left\{\Delta \varepsilon_{n}^{T}\right\}$ is the thermal strain increment, $\left\{\omega_{\text {in }}\right\}$ is the implicit integral operator, $\left[D_{n}\right]$ is the viscoelastic modulus, $[Q]$ is Poisson's ratio matrix, $\gamma$ is the linear expansion coefficient, and $\{\Delta T\}$ is the temperature difference [4].

\subsection{Finite Element Formulations for Soil Consolidation Theory}

2.2.1. MCC Model. According to the classical elastoplastic theory of geotechnical engineering, the stress-strain relationship is shown as follows [49]:

$$
\{\mathrm{d} \sigma\}=\left[C^{e}\right]+\left[\{\mathrm{d} \varepsilon\}-\left\{\mathrm{d} \varepsilon^{p}\right\}\right]
$$

In addition,

$$
\left[C^{e}\right]=\frac{3 K(1-\mu)}{1+\mu}\left[\begin{array}{cccccc}
1 & \frac{\mu}{1-\mu} & \frac{\mu}{1-\mu} & 0 & 0 & 0 \\
\frac{\mu}{1-\mu} & 1 & \frac{\mu}{1-\mu} & 0 & 0 & 0 \\
\frac{\mu}{1-\mu} \frac{\mu}{1-\mu} & 1 & 0 & 0 & 0 \\
0 & 0 & 0 & \frac{1-2 \mu}{2(1-\mu)} & 0 & 0 \\
0 & 0 & 0 & 0 & \frac{1-2 \mu}{2(1-\mu)} & 0 \\
0 & 0 & 0 & 0 & 0 & \frac{1-2 \mu}{2(1-\mu)}
\end{array}\right]
$$

where $\{\mathrm{d} \sigma\}$ represents the stress increment, $\{\mathrm{d} \varepsilon\}$ represents the total strain increment, $\{\mathrm{d} \varepsilon p\}$ represents the plastic strain increment, $\left[C^{e}\right]$ represents the elastic-stiffness matrix, $K$ represents the volumetric modulus, and $\mu$ represents Poisson's ratio.

For an isotropic hardening material, the yield function is given as follows [49]:

$$
f\left(\sigma_{i j}, A\right)=0
$$

where $A$ is the hardening parameter for saturated soil. Using the chain rule for the differential, equation (11) can be converted as follows:

$$
\mathrm{d} f=\left\{\frac{\partial f}{\partial \sigma}\right\}^{T}\{\mathrm{~d} \sigma\}+\frac{\partial f}{\partial A}\left\{\frac{\partial f}{\partial \varepsilon^{p}}\right\}^{T}\left\{\mathrm{~d} \varepsilon^{p}\right\} .
$$

According to the flow rule, the plastic strain increment is defined as the following equation [50]: 


$$
\mathrm{d} \varepsilon^{p}=\Lambda^{\prime}\left\{\frac{\partial g}{\partial \sigma}\right\}
$$

where

$$
\Lambda^{\prime}=\frac{\{\partial f / \partial \sigma\}^{T}\left[C^{e}\right]\{\mathrm{d} \varepsilon\}}{-(\partial f / \partial A)\left\{\partial A / \partial \varepsilon^{p}\right\}^{T}\{\partial g / \partial \sigma\}+\{\partial f / \partial \sigma\}^{T}\left[C^{e}\right]\{\partial g / \partial \sigma\}},
$$

where $g$ is the plastic potential function and $\Lambda^{\prime}$ is the plastic multiplier.

In the MCC model, the volumetric modulus $K$ is related to the stress history [51], and the hardening parameter $A$ is the volumetric plastic strain [46]:

$$
\begin{aligned}
K & =\frac{1+e_{0}}{\bar{\kappa}} p^{\prime}, \\
A & =\varepsilon_{v}^{p} .
\end{aligned}
$$

In these equations, $e_{0}$ represents the initial void ratio, $\bar{\kappa}$ represents the unloading-reloading index of soft soils, and $p^{\prime}$ represents the mean effective stress.

The yield function of the MCC model is given as follows [49]:

$$
f=\frac{\bar{\lambda}-\bar{\kappa}}{1+e_{0}} \ln \frac{p^{\prime}}{p_{0}}+\frac{\bar{\lambda}-\bar{\kappa}}{1+e_{0}} \ln \left(1+\frac{q^{2}}{M^{2} p^{\prime 2}}\right)-\varepsilon_{v}^{p}=0,
$$

where $\bar{\lambda}$ represents the virgin compression index, $p_{0}$ represents the preconsolidation pressure, $q$ represents the deviatoric stress, and $M$ represents the critical-state parameter.

In the Cartesian coordinate system, the mean effective stress $p^{\prime}$ and the deviatoric stress $q$ can be obtained by the following equations, respectively [52].

$$
\begin{aligned}
& p^{\prime}=\frac{1}{3}\left(\sigma_{x}^{\prime}+\sigma_{y}^{\prime}+\sigma_{z}^{\prime}\right) \\
& q=\sqrt{\sigma_{x}^{\prime 2}+\sigma_{y}^{\prime 2}+\sigma_{z}^{\prime 2}+3\left(\tau_{x y}^{2}+\tau_{y z}^{2}+\tau_{z x}^{2}\right)-\left(\sigma_{x}^{\prime} \sigma_{y}^{\prime}+\sigma_{y}^{\prime} \sigma_{z}^{\prime}+\sigma_{z}^{\prime} \sigma_{x}^{\prime}\right)}
\end{aligned}
$$

According to the consistency condition, the derivatives of the yield function $f$ and plastic potential function $g$ with respect to stress $\sigma$ are [49]

$$
\left\{\frac{\partial f}{\partial \sigma}\right\}=\left\{\frac{\partial g}{\partial \sigma}\right\}=\frac{\bar{\lambda}-\bar{\kappa}}{\left(1+e_{0}\right) p^{\prime}}\left(\frac{M^{2}-\eta^{2}}{M^{2}+\eta^{2}}+\frac{2 \eta}{M^{2}+\eta^{2}}\right),
$$

where

$$
\eta=\frac{q}{p^{\prime}}
$$

Based on equations (13) and (14), equation (9) can be converted into the following equation:

$$
\{\mathrm{d} \sigma\}=\left(\left[C^{e}\right]-\frac{\left[C^{e}\right]\{\partial g / \partial \sigma\}\{\partial f / \partial \sigma\}^{T}\left[C^{e}\right]}{-(\partial f / \partial A)\left\{\partial A / \partial \varepsilon^{p}\right\}^{T}\{\partial g / \partial \sigma\}+\{\partial f / \partial \sigma\}^{T}\left[C^{e}\right]\{\partial g / \partial \sigma\}}\right)\{\mathrm{d} \varepsilon\},
$$

where

$$
\begin{gathered}
\frac{\partial f}{\partial A}=-1 \\
\left\{\frac{\partial A}{\partial \varepsilon^{p}}\right\}=\left\{\begin{array}{l}
\frac{\partial A}{\partial \varepsilon_{v}^{p}} \\
\frac{\partial A}{\partial \varepsilon_{d}^{p}}
\end{array}\right\}=\left\{\begin{array}{l}
1 \\
0
\end{array}\right\} .
\end{gathered}
$$

According to equation (22), the relationship between stress and strain increment of the MCC model is described as follows.

The thermal strain increment is calculated by equation (22):

2.2.2. Elastoplastic Consolidation. For the saturated continuous soil, the equilibrium equation can be discretized into the following form [47]:

$$
[K]\{\delta\}=\{\bar{R}\},
$$

where $[K]$ represents the stiffness matrix, $\{\delta\}$ represents the displacement vector at nodal points, and $\{\bar{R}\}$ represents the load vector. The fluid flow equation is given as [47]

$$
[H]\{\bar{q}\}=\left\{\bar{R}_{p}\right\}
$$


where $[H]$ represents the fluid flow matrix, $\{\bar{q}\}$ represents the pore water pressure vector at nodal points, and $\left\{\bar{R}_{p}\right\}$ represents the applied flux.

Based on the theory of seepage, the pore water pressure $p_{w}$ exerted on the soil skeleton can be expressed as follows [43]:

$$
\left\{X_{i}\right\}=-\left\{\frac{\partial p_{w}}{\partial X_{i}}\right\} .
$$

Equation (28) can be discretized into the following form using the FEM:

$$
\left\{X_{i}\right\}=-\left\{\frac{\partial}{\partial X_{i}}\right\}\left[\bar{N}_{p}\right]\{\bar{q}\},
$$

where $\left[\bar{N}_{p}\right]$ represents the shape function for pore water pressure. According to Biot's theory, the nodal force $\{F\}_{p}$ is defined as the following equation [53]:

$$
\{F\}_{p}=\int_{V}[\bar{N}]^{T}\left\{X_{i}\right\} \mathrm{d}_{V}=-[L]^{T}\{\bar{q}\} .
$$

In addition,

$$
[L]^{T}=\int_{V}[\bar{N}]^{T}\left\{\frac{\partial}{\partial X_{i}}\right\}\left[\bar{N}_{p}\right] \mathrm{d} V,
$$

where $[\bar{N}]$ represents the displacement shape function and $[L]$ represents the coupling matrix. Therefore, equation (26) can be converted into the following equation:

$$
[K]\{\delta\}-[L]^{T}\{\bar{q}\}=\{\bar{R}\} .
$$

For a porous elastic medium, the continuity equation can be expressed as follows:

$$
Q=\dot{\varepsilon_{i i}}=-\frac{\partial}{\partial t}\left(\frac{\partial u}{\partial x}+\frac{\partial v}{\partial y}+\frac{\partial w}{\partial z}\right)
$$

where $\dot{\varepsilon_{i i}}$ represents the rate of volume change. The discrete form of equations (2)-(33) is given in the following equation:

$$
Q=-\frac{\partial}{\partial t}\left\{\frac{\partial}{x_{i}}\right\}^{T}[\bar{N}]\{\delta\} .
$$

Considering the fluid-skeleton compatibility, the fluid flow equation is converted into the following equation [47]:

$$
[H]\{\bar{q}\}-[L] \frac{\partial}{\partial t}\{\delta\}=\left\{\bar{R}_{p}\right\},
$$

where

$$
[L] \frac{\partial}{\partial t}\{\delta\}=-\int_{V}\left[\bar{N}_{p}\right]^{T} Q \mathrm{~d} V .
$$

In a time increment $\Delta t\left(t_{1} \longrightarrow t_{2}\right)$, equations (2)-(35) can be solved using the finite difference approximation [41].

$$
[H]\left\{\bar{q}_{1}+\beta\left(\bar{q}_{2}-\bar{q}_{1}\right)\right\} \Delta t-[L]\left\{\delta_{2}-\delta_{1}\right\}=0,
$$

where $\beta$ corresponds to the particular integration rule. The assembled form of equations (32) and (37) is shown as follows [41]:

$$
\left[\begin{array}{cc}
K & -[L]^{T} \\
-L & \beta \Delta t H
\end{array}\right]\left\{\begin{array}{l}
\delta_{2} \\
\bar{q}_{2}
\end{array}\right\}=\left\{\begin{array}{c}
\bar{R}_{2} \\
-L \delta_{1}-(1-\beta) \Delta t H \bar{q}_{1}
\end{array}\right\} .
$$

In addition,

$$
[K]=\int_{V}[B]^{T}\left[C^{e}\right][B] \mathrm{d}_{V},
$$

where $[B]$ represents the strain rate-velocity matrix. For the elastoplastic MCC model, $\left[C^{e}\right]$ can be suited by $\left[C^{e p}\right]$ [54].

\section{The Optimization Problem Statement}

3.1. Geometric Description of the Ship Lock Head. Parametric modelling is the basis for structural optimization design. The ship lock head is a symmetrical structure along the water flow direction. Therefore, half of the geometric model was established. As shown in Figure 1(a), a typical lock head consists of the bottom plate, the corridor layer, the empty-box layer, and the second-stage concrete. The model of the lock head-soft foundation-backfilled soil system is shown in Figure 1(b).

The horizontal and vertical views of the bottom plate are shown in Figure 2. The bottom plate is a regular structure. It can be established by determining $X_{p i}(i=1-3), Y_{p i}(i=1-8)$, and $Z_{p i}(i=1-6)$. As shown in Figure 3, the design of the second-stage concrete also needs to determine the central angles $\alpha_{q i}(i=1-3)$, the arc radii $R_{q i}(i=1-2)$, and the length parameters $L_{q i}(i=1-7)$ [4]. The corridor layer section is shown in Figure 4.

3.2. Design Variables. Designers save concrete materials by setting up empty boxes in the lock head. According to this method, 34 design variables $\left(x_{1}-x_{15}, y_{1}-y_{12}\right.$, and $\left.z_{1}-z_{7}\right)$ were distinguished in the $x-, y$-, and $z$-directions [4], as displayed in Figure 5.

3.3. Objective Function and Constraints. The purpose of structural optimization is to find the optimal design that meets the stability and financial requirements. In this work, the lock head volume was taken as the objective function. The optimization problem can be expressed as follows:

$$
\left\{\begin{array}{l}
\text { minimize: } A(X), \\
\text { subjected to: } \varphi_{j}(X) \leq 0, \\
X_{i \min } \leq X \leq X_{i \max },
\end{array}\right.
$$

where $X=\left(x_{1}, \ldots, x_{15}, y_{1}, \ldots, y_{12}, z_{1}, \ldots, z_{7}\right)$ is the updating design variables, $A(X)$ is the volume function, $j$ is the number of constraints, $X_{i \min }$ is the lower boundary of $X$, and $X_{i \max }$ is the upper boundary of $X$.

According to the previous research [4], three types of constraints should be satisfied, which are formulated as follows: 

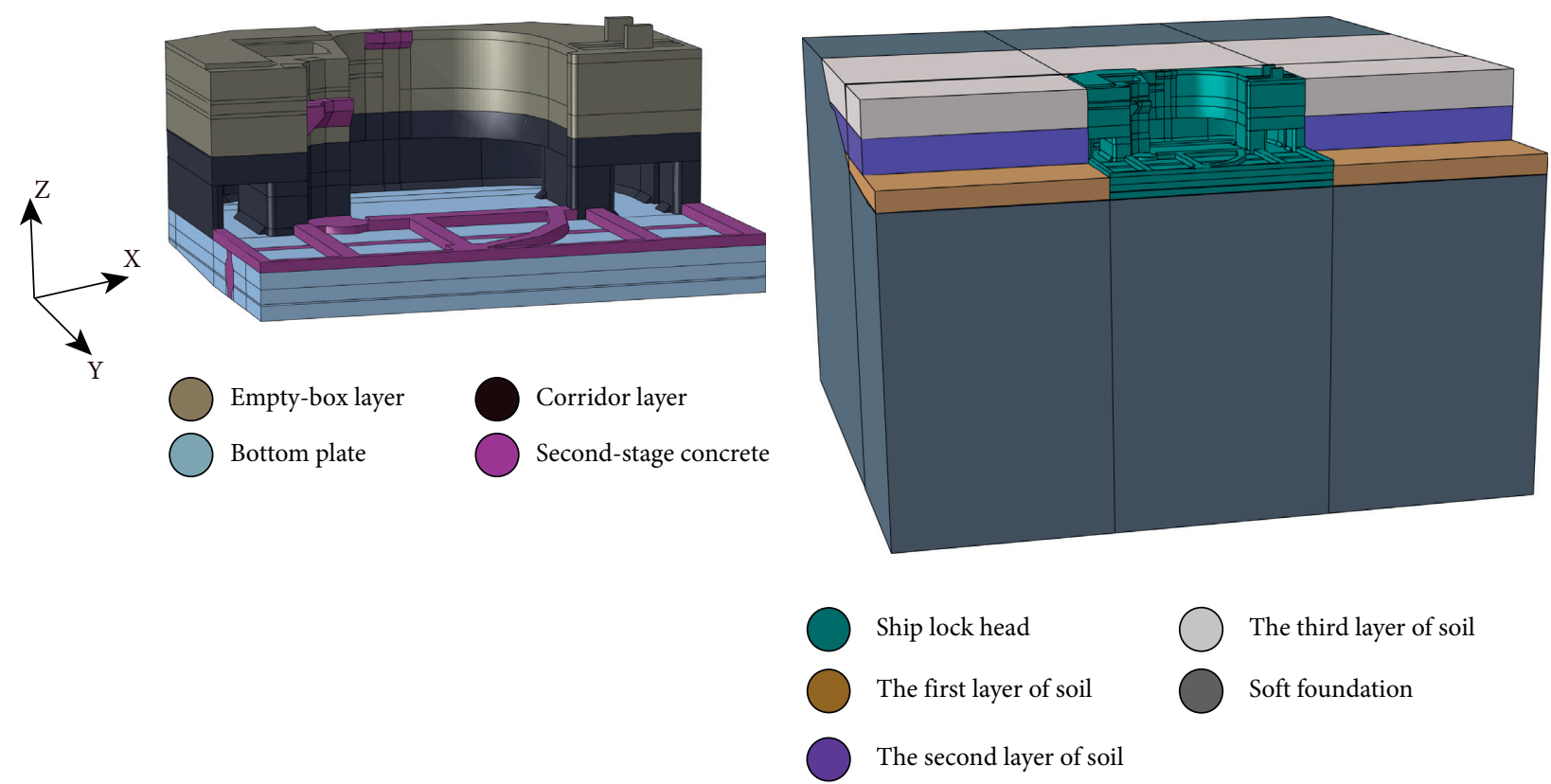

(a)

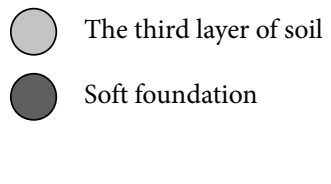

(b)

FIGURE 1: Schematics of the spatial (a) ship lock head and (b) lock head-soft foundation-backfilled soil system.

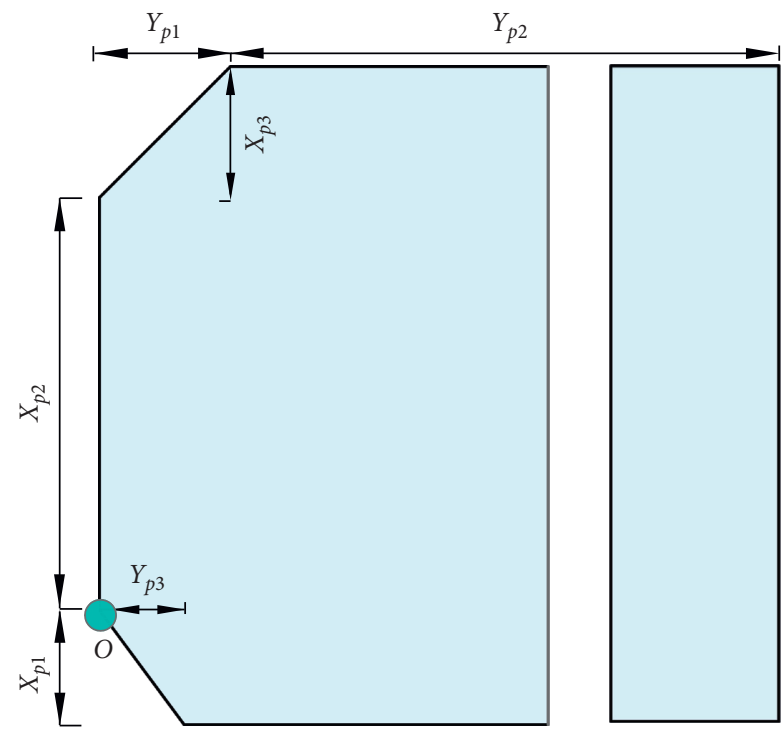

(a)

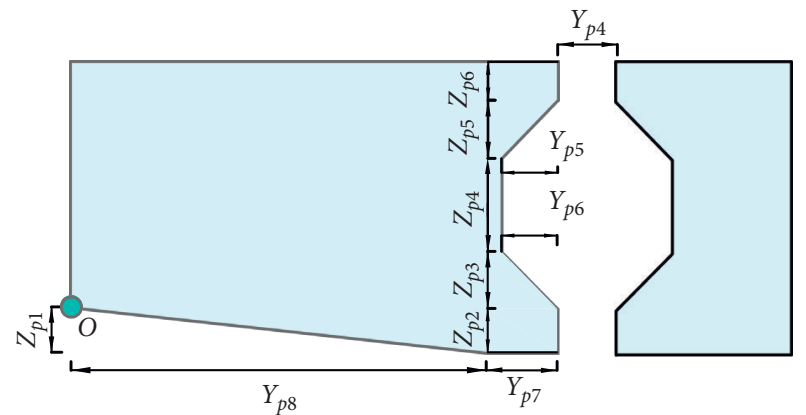

(b)

Figure 2: The basic dimensions of the bottom plate. (a) Plane figure of the bottom plate. (b) Sectional drawing of the bottom plate.

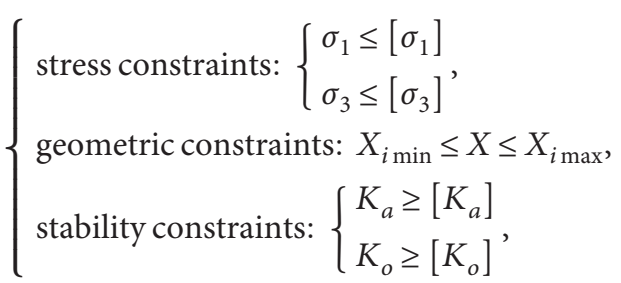

where $\sigma_{1}$ and $\sigma_{3}$ represent the maximum principal tensile stress and the maximum principal stress, respectively. Moreover, $\left[\sigma_{1}\right]$ and $\left[\sigma_{3}\right]$ represent allowable values, respectively. $K_{a}$ and $K_{o}$ represent the safety factors of the antisliding stability and anti-overturning stability, respectively. $\left[K_{a}\right]$ and $\left[K_{o}\right]$ represent allowable values, respectively. 


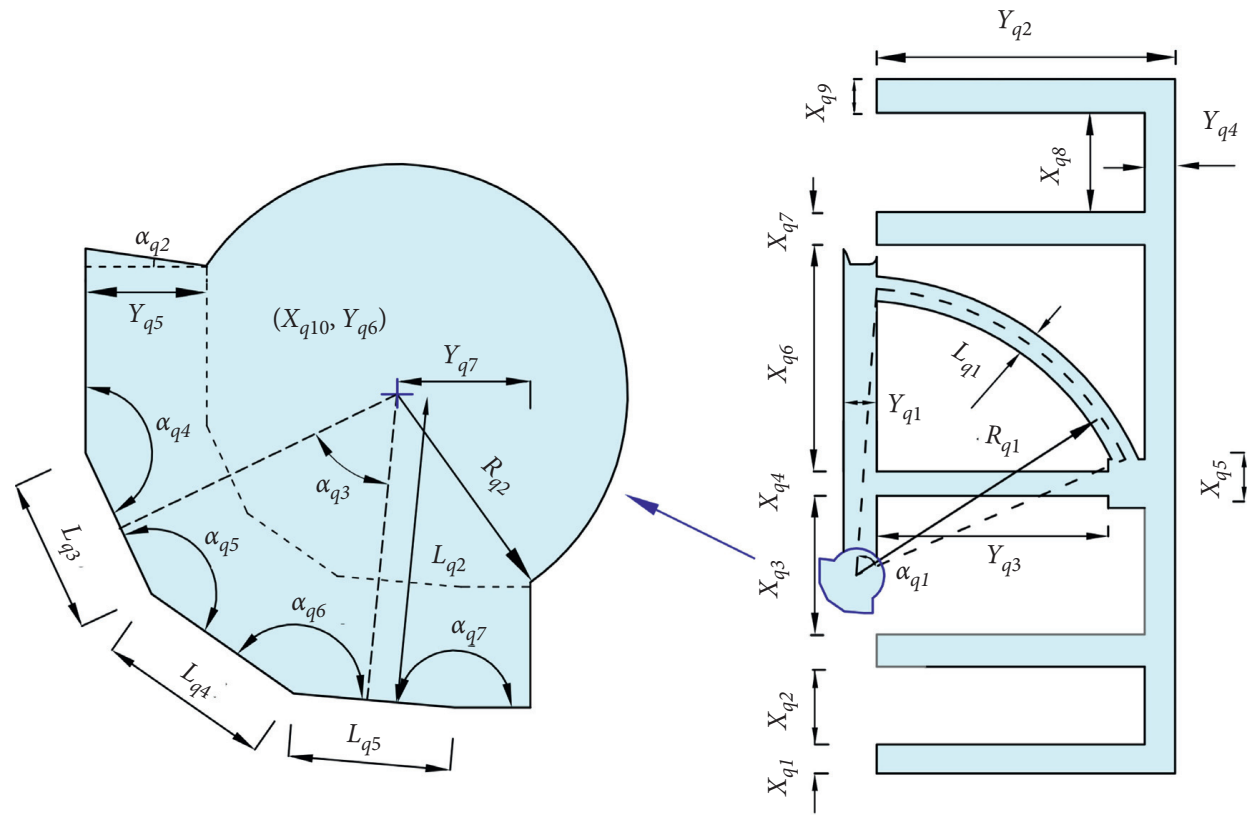

FIgURE 3: The second-stage concrete section.
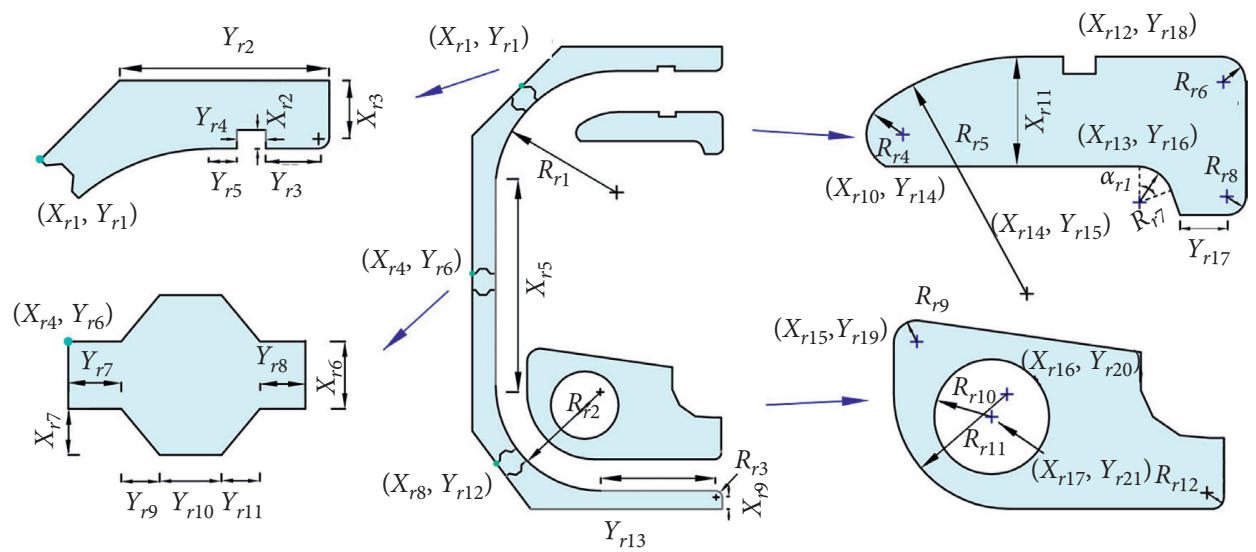

FIgURE 4: The corridor layer section.

\section{Concepts of Particle Swarm Optimization (PSO), Whale Optimization Algorithm (WOA), Enhanced Whale Optimization Algorithm (EWOA), and Differential Evolution Algorithm (DE)}

4.1. Concept of PSO. The PSO is a swarm intelligence-based algorithm proposed by Kennedy and Eberhart [10]. It was derived from observing the bird predation behaviour. PSO uses particles to represent some candidate solutions to the optimization problem in the search space. Position, velocity, and the memory mechanism are three characteristics of each particle [55]. Initially, the particles are randomly generated within the ranges of design variables. The PSO evaluates each particle's fitness value by calculating the objective function. Then, the position of each design variable is updated by the following equations:

$$
X_{i, j}^{k+1}=X_{i, j}^{k}+V_{i, j}^{k+1}
$$

In addition,

$$
V_{i, j}^{k+1}=w_{k} V_{i, j}^{k}+C_{1} \cdot r_{1}\left(P_{b i, j}^{k}-X_{i, j}^{k}\right)+C_{2} \cdot r_{2}\left(g_{b i, j}^{k}-X_{i, j}^{k}\right),
$$

where $X_{i, j}^{k}$ is the current $j^{\text {th }}$ design variable of particle $i$ at the $k^{\text {th }}$ iteration, $V_{i, j}^{k}$ is the corresponding velocity of the $j^{\text {th }}$ design variable, $P_{b i, j}^{k}$ is the best position at the $k^{\text {th }}$ iteration, $g_{b i, j}^{k}$ is the global best position, $r_{1}$ and $r_{2}$ are random numbers between $[0,1], C_{1}$ and $C_{2}$ are user-supplied coefficients, and $w_{k}$ is the inertia weight. In this study, the inertia weight is defined as follows:

$$
w_{k}=w_{\max }-\frac{w_{\max }-w_{\min }}{\text { It max }} \cdot k,
$$




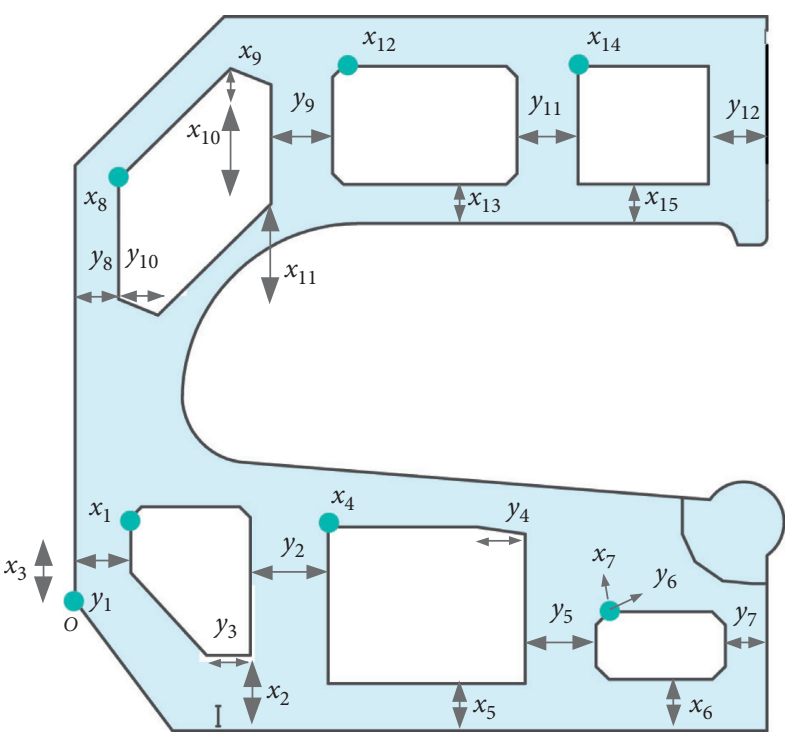

(a)

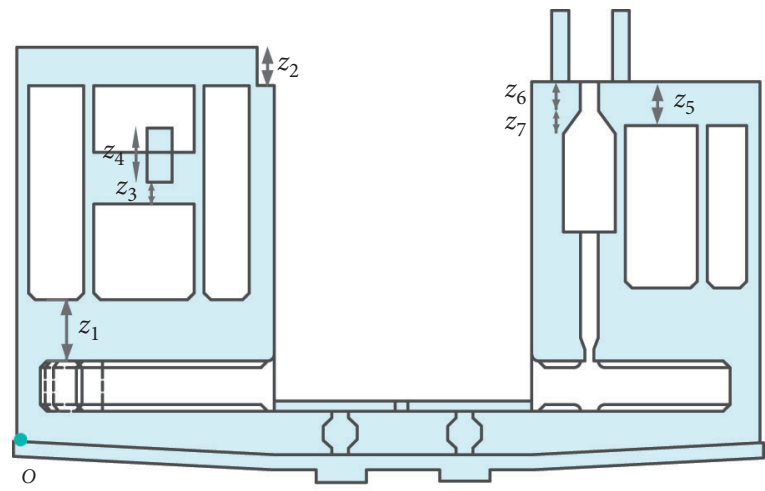

(b)

Figure 5: Design variables. (a) Horizontal view. (b) Elevation view.

where $w_{\max }$ is the maximum value of the inertia weight and $w_{\min }$ is the minimum value of the inertia weight. It max is the maximum generation, which is the termination criterion of this study.

4.2. Concept of WOA. The WOA mimics the bubble-net hunting behaviour of humpback whales. The unique hunting model is shown in Figure 6. The WOA consists of two phases: the exploitation phase and the exploration phase [21]. The mathematical models of the two stages are discussed in the following sections.

4.2.1. Exploitation Phase. As shown in Figure 7, the shrinking encircling mechanism and bubble-net spiral attacking mechanism are included in the exploitation phase. In WOA, the global best position is assumed as the target prey of the current generation, and other candidates will update their positions in a shrinking encircling manner. The mathematical model of the shrinking encircling mechanism is shown as follows:

$$
\begin{aligned}
& X_{i, j}^{k+1}=g_{b i, j}^{k}-A D_{i, j}^{k+1}, \\
& D_{i, j}^{k+1}=\left|C \cdot g_{b i, j}^{k}-X_{i, j}^{k}\right|,
\end{aligned}
$$

where $A$ and $C$ are coefficients of WOA and can be calculated as follows:

$$
\left\{\begin{array}{l}
A=2 a r-a, \\
C=2 r, \\
a=2-k \frac{2}{I t \max },
\end{array}\right.
$$

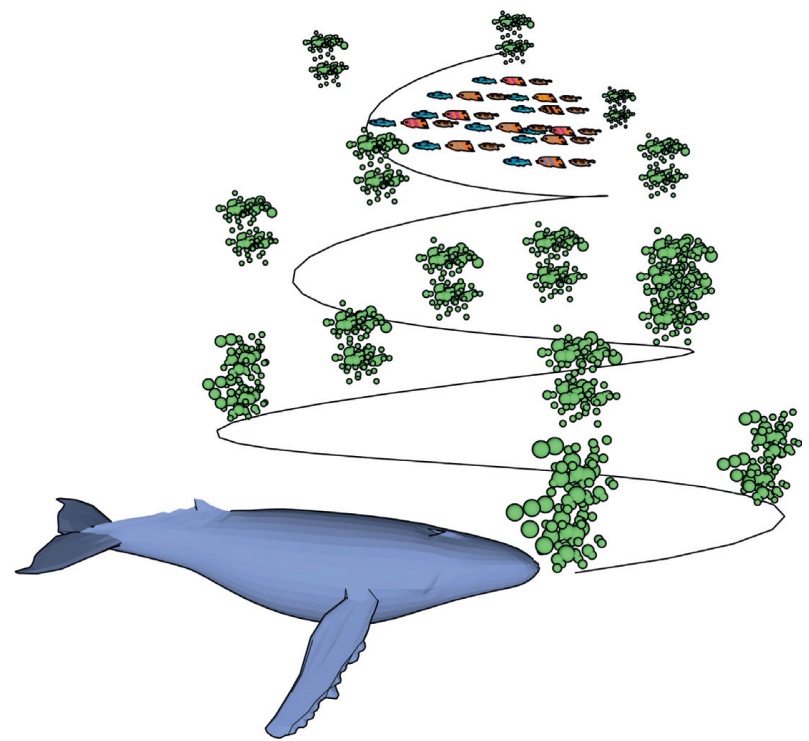

FIGURE 6: Unique bubble-net spiral hunting behaviour.

where $r$ is a random number in the interval of $[0,1]$. To simulate the bubble-net attacking behaviour of humpback whales, a spiral equation is created as follows:

$$
X_{i, j}^{k+1}=D_{i, j}^{\prime k+1} \cdot e^{b l} \cdot \cos (2 \pi l)+g_{b i, j}^{k} .
$$

In this equation, $D_{i, j}^{\prime k+1}=\left|g_{b i, j}^{k}-X_{i, j}^{k}\right|, l$ is a random number in the interval of $[-1,1]$, and constant $b$ defines the spiral shape. The humpback whales can swim around their prey in the above two paths at the same time. The mathematical model of this process is shown as follows:

$$
X_{i, j}^{k+1}= \begin{cases}g_{b i, j}^{k}-A D_{i, j}^{k+1} & \text { if prob }<0.5, \\ D_{i, j}^{\prime k+1} \cdot e^{b l} \cdot \cos (2 \pi l)+g_{b i, j}^{k} & \text { if prob } \geq 0.5 .\end{cases}
$$




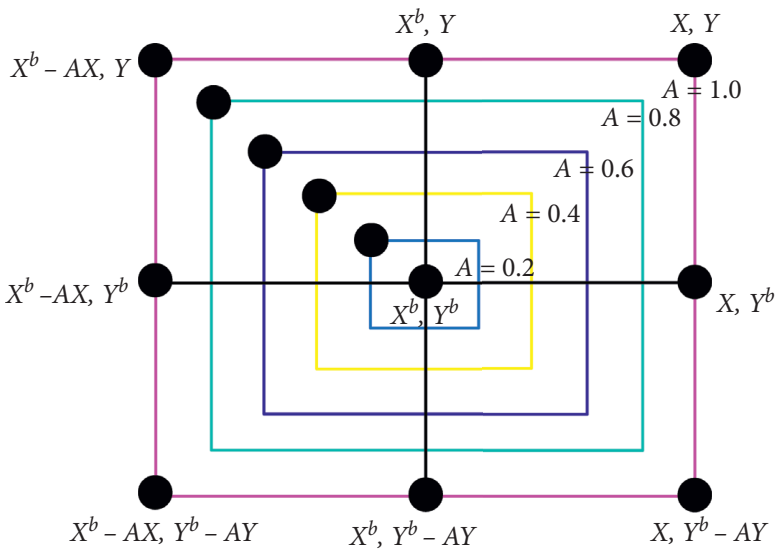

(a)

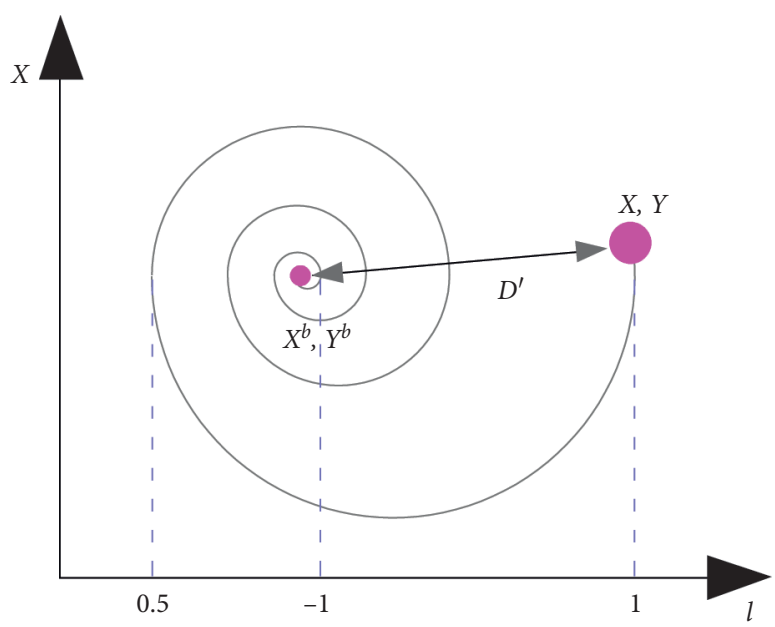

(b)

FIgURE 7: Exploitation phase in WOA. (a) Shrinking encircling mechanism. (b) Bubble-net spiral attacking mechanism.

4.2.2. Exploration Phase. To expand the searching area, the WOA updates each design variable's position using a randomly selected candidate when $|A| \geq 1$. The mathematical model for the second phase is represented by equations (50) and (51):

$$
\begin{gathered}
X_{i, j}^{k+1}=X_{r i, j}^{k}-A D_{i, j}^{\prime k+1}, \\
D_{i, j}^{\prime \prime k+1}=\left|C \cdot X_{r i, j}^{k}-X_{i, j}^{k}\right|,
\end{gathered}
$$

where $X_{r i, j}^{k}$ represents a randomly selected search agent in the current population. The flowchart of WOA is presented in Figure 8(a).

4.3. Concept of EWOA. The WOA has an effective global search capability. In order to enhance the WOA in terms of reliability, EWOA was proposed. The EWOA maintains the simplicity of the WOA. In the exploitation phase, to maintain a balance between the diversity and intensification of search results, equation (45) is replaced as follows [23]:

$$
\begin{aligned}
X_{i, j}^{k+1} & =g_{b i, j}^{k}-A D_{i, j}^{\prime \prime \prime k+1}, \\
D_{i, j}^{\prime \prime \prime} k+1 & =r\left|X_{i, j}^{k}\right| .
\end{aligned}
$$

In the exploration phase, each candidate randomly changes the value of a design variable with a probability $p^{\prime \prime}$ :

$$
p^{\prime \prime}=0.3\left(1-\frac{k}{\text { It } \max }\right) \text {. }
$$

For candidate $i$, the design variable is changed when a random number $q$ is less than probability $p^{\prime \prime}$. The mathematical model of this process is shown as follows [23]:

$$
X_{i, j}^{k+1}=\left\{\begin{array}{l}
X_{j \text { min }}+\operatorname{random} \cdot\left(X_{j \max }-X_{j \min }\right), \quad q<p^{\prime \prime}, \\
X_{i, j}^{k}, \quad q \geq p^{\prime \prime},
\end{array}\right.
$$

where random and $q$ represent random numbers between $[0$, 1], respectively. $X_{j \min }$ and $X_{j \max }$ represent the minimum value and the maximum value of the $j^{\text {th }}$ design variable, respectively. The flowchart of EWOA is presented in Figure 8(b).

4.4. Concept of DE. The DE is a simple population-based evolutionary algorithm proposed by Storn and Price [25]. Similar to PSO, it starts from randomly generating an initial population within the ranges of design variables [56]. The mutation process is to create a mutated vector $Y_{i, j}^{k+1}$ according to equation (56). The crossover process is to create a trial vector $Z_{i, j}^{k+1}$, as described in equation (57) [25]. In the selection process, whether the trial vector should be selected for the next generation can be determined according to equation (58) [8].

$$
\begin{aligned}
& Y_{i, j}^{k+1}=X_{\mathrm{ran} 1, j}^{k}+F\left(X_{\mathrm{ran} 2, j}^{k}-X_{\mathrm{ran} 3, j}^{k}\right), \\
& Z_{i, j}^{k+1}= \begin{cases}Y_{i, j}^{k+1} & \text { if }(\operatorname{rand}(i) \leq \mathrm{CR}) \text { or }(i=\operatorname{rnbr}(i)), \\
X_{i, j}^{k} & \text { if }(\operatorname{rand}(i)>\mathrm{CR}) \text { and }(i \neq \operatorname{rnbr}(i)),\end{cases} \\
& X_{i, j}^{k+1}= \begin{cases}Z_{i, j}^{k+1} & \text { if } A\left(Z_{i, j}^{k+1}\right) \leq A\left(X_{i, j}^{k}\right), \\
X_{i, j}^{k}, & \text { otherwise, }\end{cases}
\end{aligned}
$$

where ran1, ran2, and ran3 are three different numbers $\in \in\{1,2, \ldots, N\}, N$ is the population size, and the randomly chosen numbers ran1, ran2, and ran3 are different from integer $i ; F$ is the scaling factor; CR is the crossover constant; and $\operatorname{rand}(i)$ and $\operatorname{rnbr}(i)$ are random numbers in the interval of $[0,1]$ and in $[1, N]$, respectively.

\section{The Proposed Algorithm}

5.1. PSO-EWOA-DE Algorithm Description. The PSOEWOA-DE algorithm is a population-based evolutionary 


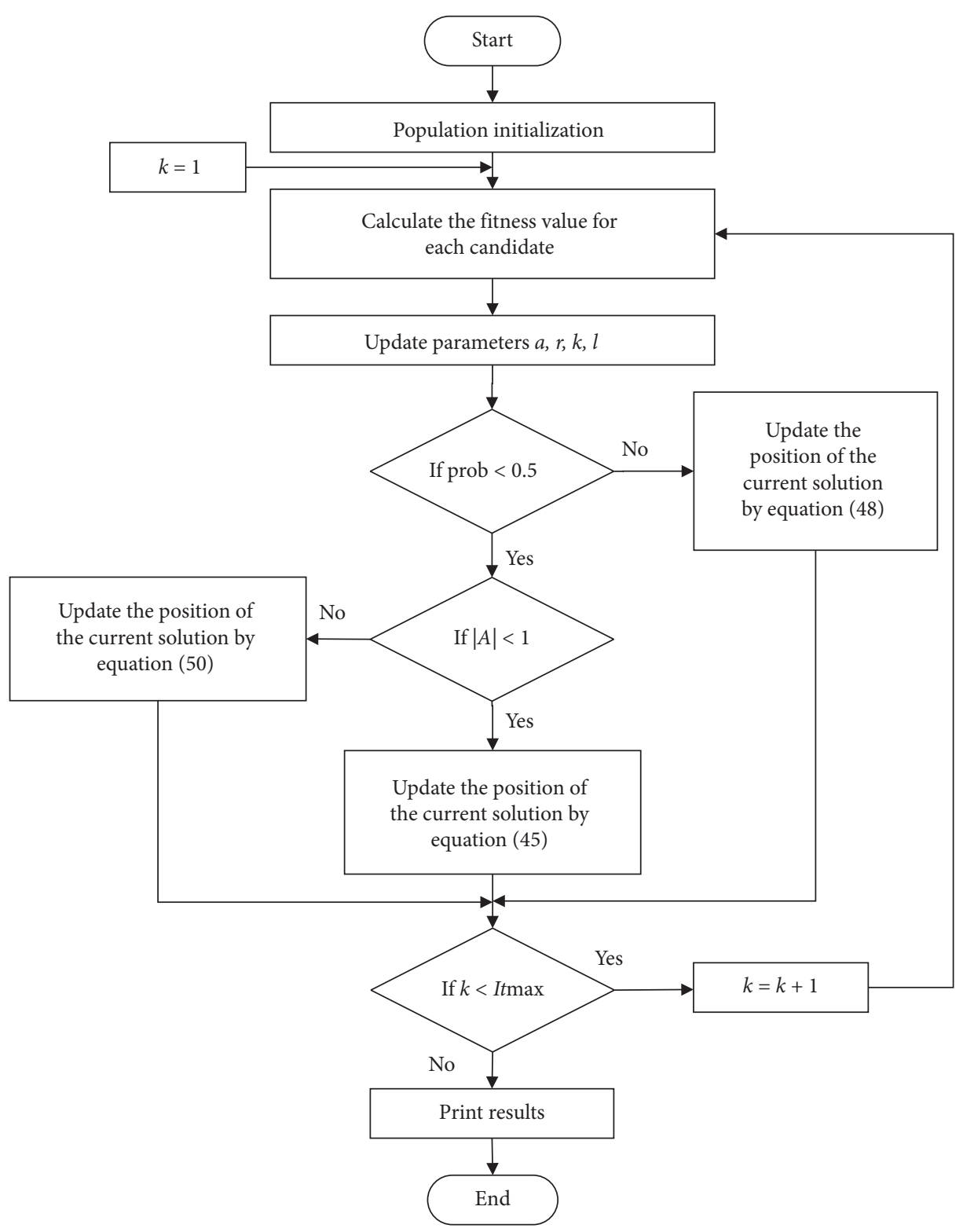

(a)

Figure 8: Continued. 


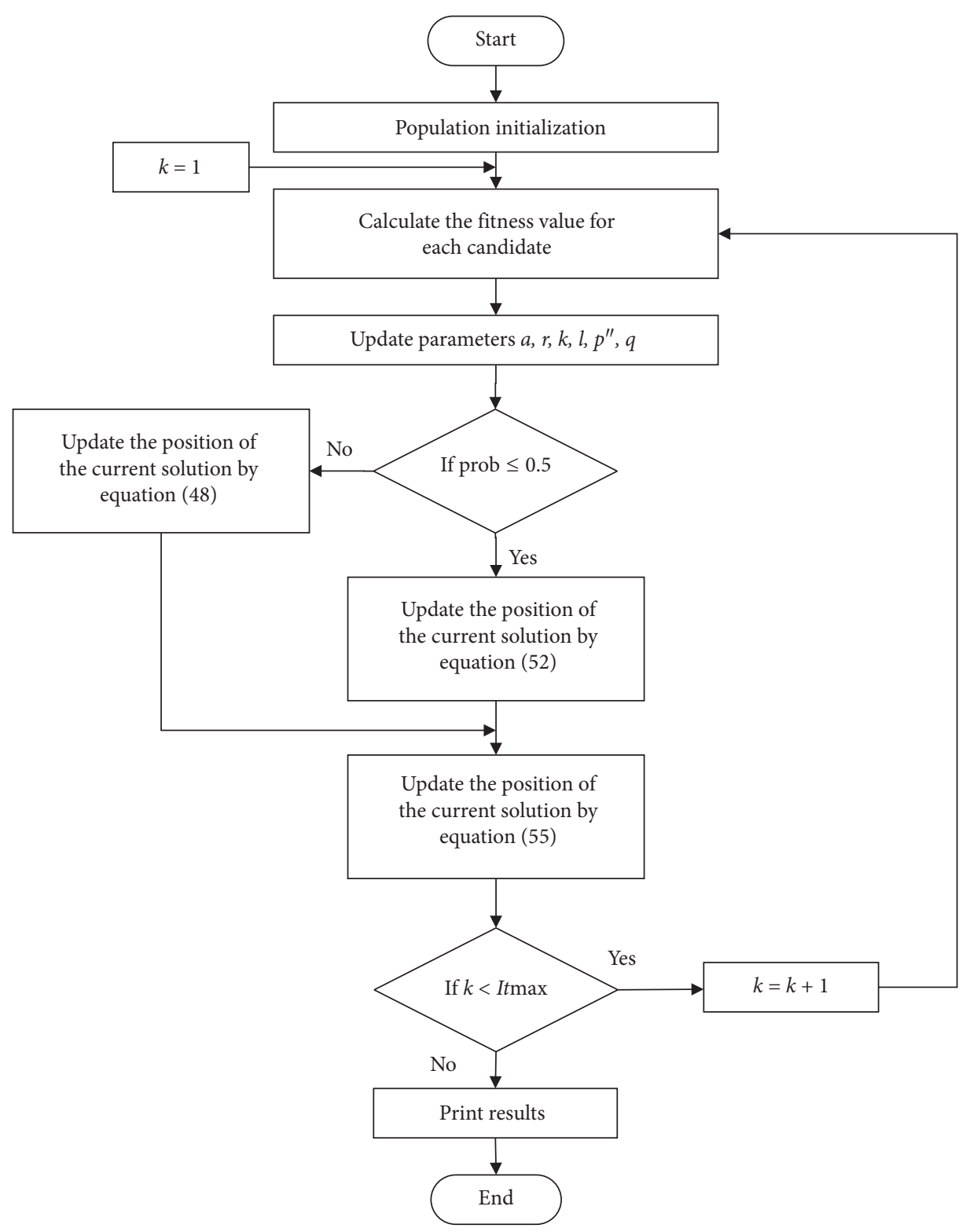

(b)

FIgURE 8: Flowcharts of the (a) WOA algorithm and (b) EWOA algorithm.

algorithm. Initially, the PSO-EWOA-DE algorithm explores the search space globally by using PSO and EWOA and then utilizes DE to fine-tune the selected solution locally. This process is repeated until the stopping criterion is met. This algorithm can ensure diversity and maintain convergence accuracy. The PSO-EWOA-DE algorithm steps are summarized as follows:

(1) Set the population size $N$ and the value range of the design variables. Then, generate the initialized population for design variables.

(2) Calculate the fitness value for each candidate.
(3) Update the parameters $a, r, k, l, p^{\prime \prime}$, and $q$ in the EWOA process and the parameters $r_{1}, r_{2}$, and $w_{k}$ in the PSO process.

(4) Generate the trial population POP_EWOA according to the EWOA process shown in Section 4.3, and calculate the fitness values $A\left(\mathrm{POP}_{\text {_EWOA }}\right)$ of population POP

(5) Generate the trial population POP ${ }_{\text {PSO }}$ according to the PSO process shown in Section 4.1, and calculate the fitness values $A\left(\mathrm{POP}_{\text {PSO }}\right)$ of population POP_PSO. 
(6) Select the trial population POP _trial according to equation (59) and the global best individual $G_{\text {best }}$ according to equation (60).

$$
\begin{aligned}
& \mathrm{POP}_{-\operatorname{trial}(i)}= \begin{cases}\mathrm{POP}_{-} \mathrm{EWOA}_{(i)} & \text { if } A\left(\mathrm{POP}_{-} \mathrm{EWOA}_{(i)}\right) \leq A\left(\mathrm{POP}_{-} \mathrm{PSO}_{(i)}\right) \\
\mathrm{POP}_{-} \mathrm{PSO}(i), & \text { otherwise, }\end{cases} \\
& G_{\text {best }}= \begin{cases}G_{\text {best_EWOA }} & \text { if } A\left(G_{\text {best_EWOA }}\right) \leq A\left(G_{\text {best_PSO }}\right), \\
G_{\text {best_PSO }}, & \text { otherwise, }\end{cases}
\end{aligned}
$$

where POP $\operatorname{trial}(i)$ is the $i^{\text {th }}$ candidate of the trial population, POP_EWOA(i) is the $i^{\text {th }}$ candidate of POP_EWOA, POP_PSO $(i)$ is the $i^{\text {th }}$ candidate of POP_PSO, $G_{\text {best_EWOA }}$ is the global best individual of $\mathrm{POP}_{\text {EWOA }}$, and $G_{\text {best_PSO }}$ is the global best individual of POP_PSO.

(7) Generate a new population for the next generation according to the DE process shown in Section 4.4.

(8) Terminate the PSO-EWOA-DE algorithm by satisfying the termination condition. If so, go to Step 9; otherwise, go to Step 2.

(9) Output the optimal solution obtained in Step 6.

The flowchart of the PSO-EWOA-DE algorithm is presented in Figure 9(a).

5.2. Optimization Procedure. This section presents a structural optimization procedure of the ship lock head structure based on the PSO-EWOA-DE algorithm. The optimization procedure was implemented by using a self-developed Python script, which was worked in Abaqus 6.14. The heat of hydration was calculated by using a user subroutine (HETVAL). Furthermore, a user subroutine (UMAT) was developed to implement the MCC model and calculate the thermal creep stress.

The structural optimization process of a ship lock head on soft soil, considering the time-varying effect of the structure and foundation, can be summarized as follows:

(1) The population size $N$ and the value range of the design variables were determined. Then, the initialized population for 34 design variables was generated.

(2) The FEM model for a ship lock head was generated. Furthermore, the initial temperature, convection conditions, construction steps, and the heat of hydration were applied to calculate the temperature field.

(3) The element type was automatically modified to calculate the initial geostress field.

(4) The pore water pressure boundaries, displacement boundaries, and design loads were applied to calculate the stress field by calling Abaqus.
(5) Three types of constraints shown in Section 3.3 were evaluated, and the fitness value was calculated.

(6) A new population was generated using the PSOEWOA-DE algorithm shown in Section 5.1.

(7) The stopping criterion was checked, and Steps 2 to 6 were repeated when $k<$ It $\max$.

(8) The optimum solution with the highest fitness obtained in Step 6 was output.

The flowchart of the structural optimization procedure is shown in Figure 9(b).

\section{Engineering Example of a Ship Lock Head}

6.1. Finite Element Model Description. The structural optimization of the proposed ship lock head during the construction period considered only the static load. The design loads of the lock head-soft foundation-backfilled soil system were gravity loads, active earth pressure, live loads, and temperature. A lock head with a width of $53.8 \mathrm{~m}$ and a height of $12.2 \mathrm{~m}$ was presented here. Table 1 lists the initial values for design variables of the lock head. The lower and upper limits for design variables are also shown in Table 1. To reduce the calculation time and improve optimization efficiency, we set value ranges for 34 design variables. The value ranges for 34 design variables were set according to the engineering example's initial sizes introduced in this paper. It ensured that each searched ship lock head's volume was smaller than the initial design during the optimization process.

The lock head density is $2400 \mathrm{~kg} / \mathrm{m}^{3}$, and Poisson's ratio is 0.167. According to the previous research [4], the elastic modulus $E\left(t^{\prime}\right)$, the creep function $C\left(t, t^{\prime}\right)$, and the heat of hydration $Q\left(t^{\prime}\right)$ of concrete are as follows:

$$
\begin{aligned}
E\left(t^{\prime}\right)= & 34.25\left[1-\exp \left(-0.28 \tau^{0.52}\right)\right] \times 10^{9} \\
C(t, \tau)= & \left\{6.39 \times\left(1+9.2 \tau^{-0.45}\right)[1-\exp (-0.3(t-\tau))]\right. \\
& \left.+14.5 \times\left(1+1.7 \tau^{-0.45}\right)[1-\exp (-0.005(t-\tau))]\right\} \\
& \times 10^{-12} \\
Q\left(t^{\prime}\right)= & 98167.48\left[1-\exp \left(-0.0033 t^{1.525}\right)\right] .
\end{aligned}
$$




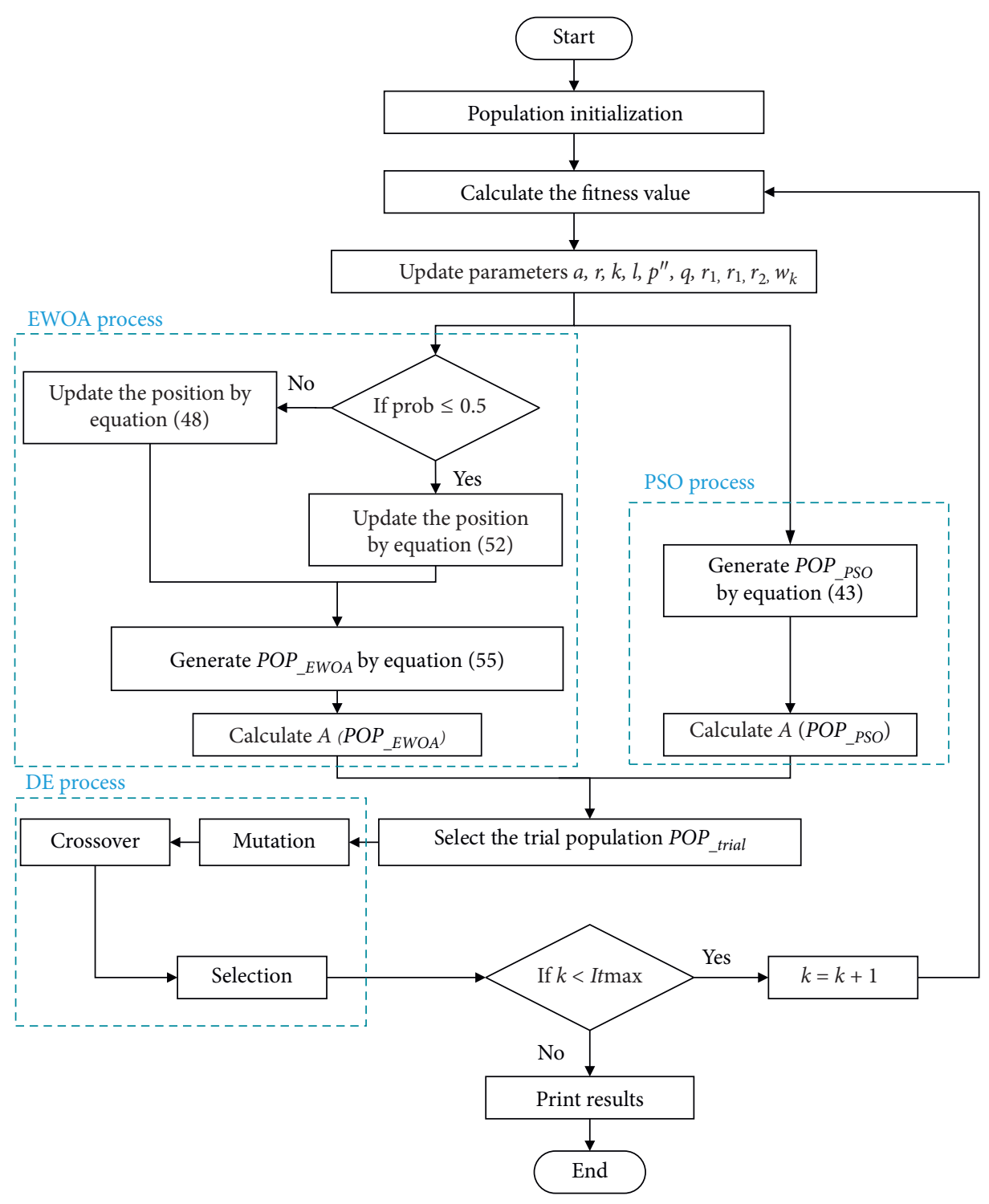

(a)

Figure 9: Continued. 


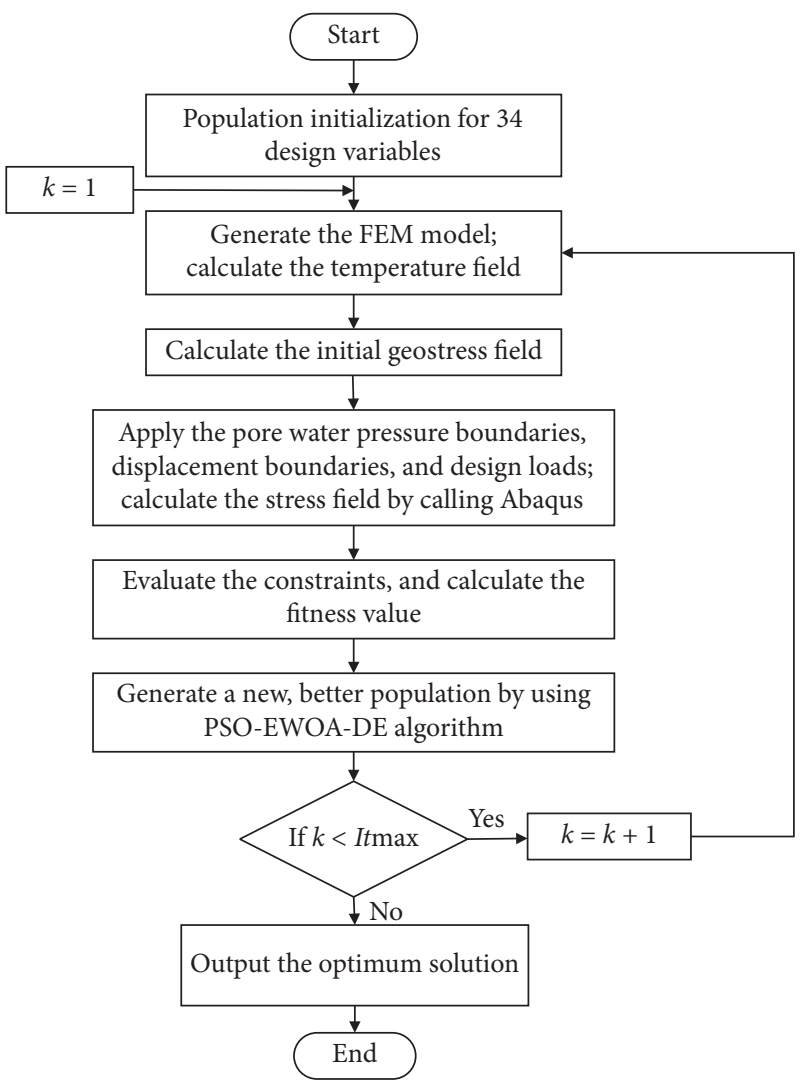

(b)

FIgURE 9: Flowcharts of the (a) PSO-EWOA-DE algorithm and (b) structural optimization procedure.

Table 2 shows the main material properties of the soft foundation and backfilled soil. Equation (62) gives the air temperature curve during the construction of the lock head:

$$
T_{a}=18.87+10.83 \cos \left[\frac{\pi(\tau-132)}{180}\right]
$$

The entire construction process of the ship lock head was 386 days. As shown in Table 3, the construction schedule was divided into 11 steps [4]. According to Kennedy and Eberhart [10], the user-supplied coefficients $C_{1}$ and $C_{2}$ of PSO were set to 2 in this study. Meanwhile, the maximum value $w_{\max }$ and the minimum value $w_{\min }$ of the inertia weight were 0.9 and 0.4 , respectively [57]. The scaling factor $F$ and the crossover constant $\mathrm{CR}$ were 0.5 and 0.55 , respectively [28]. The population size $N$ was 40 , and the maximum iteration It max was 30 .

6.2. Optimization Results. In this section, the previously described procedure was used to optimize the ship lock head. The optimization work met the requirements of China. For 60 runs of PSO [10], WOA [15], DE [25], EWOA [23], PSO-DE [28], and PSO-EWOA-DE algorithms, each algorithm's convergence history is depicted in Figure 10. The PSO-EWOA-DE converged after 13 iterations, which was faster than others. Furthermore, PSO-EWOA-DE produced the best solution when other algorithms were trapped into a local optimal solution, meaning PSO-EWOA-DE was more suitable for the structural optimization of the lock head.

Table 1 lists the optimum design variables of the lock head. Compared with the initial design, it can be found that the optimal design reduced the height of the corridor layer's coverslip and correspondingly increased the height of the empty box. Therefore, the volume of the corridor layer was significantly reduced, and the volume of the empty-box layer was slightly increased. The results of the optimization are listed in Table 4. As seen, the PSO-EWOA-DE leads to a $10.45 \%$ reduction in the structure volume when compared with the initial design.

The antisliding safety factors and the anti-overturning safety factors for the optimal results of the PSO, WOA, DE, EWOA, PSO-DE, and PSO-EWOA-DE are summarized in Figure 11. The optimal result of the PSO-EWOA-DE had the smallest safety factors under safe conditions. It verified that the optimal volume of the ship lock head searched by the PSO-EWOA-DE was the smallest.

Figure 12 demonstrates the convergence histories of the PSO-EWOA-DE algorithm and the EWOA algorithm when the population sizes $N$ were $10,20,30,40$, and 50 , respectively. As shown in Figure 12(a), it could be seen that, with the increase in population sizes, the results searched by the PSO-EWOA-DE algorithm gradually approached the 
TABLE 1: Range of design variables.

\begin{tabular}{|c|c|c|c|c|}
\hline Design variable & Lower limits (m) & Upper limits (m) & Initial values $(\mathrm{m})$ & Optimum values (m) \\
\hline$x_{1}$ & 3.29 & 4.59 & 4.59 & 4.3 \\
\hline$x_{2}$ & 0.69 & 1.29 & 1.29 & 0.69 \\
\hline$x_{3}$ & 0.06 & 0.24 & 0.24 & 0.102 \\
\hline$x_{4}$ & 3.71 & 3.91 & 3.71 & 3.91 \\
\hline$x_{5}$ & 0.06 & 0.71 & 0.71 & 0.506 \\
\hline$x_{6}$ & 0.06 & 0.69 & 0.69 & 0.6 \\
\hline$x_{7}$ & -1.31 & -0.51 & -0.51 & -0.78 \\
\hline$x_{8}$ & 17.92 & 18.19 & 17.92 & 18.139 \\
\hline$x_{9}$ & 0.165 & 0.19 & 0.165 & 0.19 \\
\hline$x_{10}$ & 3.75 & 3.89 & 3.75 & 3.89 \\
\hline$x_{11}$ & 3.79 & 3.9 & 3.79 & 3.88 \\
\hline$x_{12}$ & 22.9 & 23.39 & 22.9 & 23.39 \\
\hline$x_{13}$ & 0.06 & 0.69 & 0.69 & 0.69 \\
\hline$x_{14}$ & 23.29 & 23.49 & 23.29 & 23.30 \\
\hline$x_{15}$ & 0.06 & 0.39 & 0.39 & 0.37 \\
\hline$y_{1}$ & 0.06 & 0.69 & 0.69 & 0.456 \\
\hline$y_{2}$ & 0.06 & 0.59 & 0.59 & 0.201 \\
\hline$y_{3}$ & 0.49 & 0.89 & 0.89 & 0.506 \\
\hline$y_{4}$ & 0.06 & 1.81 & 1.81 & 0.348 \\
\hline$y_{5}$ & 0.11 & 1.16 & 1.16 & 0.152 \\
\hline$y_{6}$ & 11.59 & 11.9 & 11.9 & 11.6 \\
\hline$y_{7}$ & 0.06 & 1.51 & 1.51 & 0.605 \\
\hline$y_{8}$ & 0.06 & 0.69 & 0.69 & 0.62 \\
\hline$y_{9}$ & 0.06 & 0.61 & 0.61 & 0.45 \\
\hline$y_{10}$ & 0.39 & 0.49 & 0.49 & 0.42 \\
\hline$y_{11}$ & 0.06 & 0.71 & 0.71 & 0.6 \\
\hline$y_{12}$ & 0.06 & 1.89 & 1.89 & 1.15 \\
\hline$z_{1}$ & 0.06 & 1.60 & 1.60 & 0.3 \\
\hline$z_{2}$ & 0.06 & 0.29 & 0.29 & 0.06 \\
\hline$z_{3}$ & 0.06 & 0.23 & 0.23 & 0.06 \\
\hline$z_{4}$ & 0.43 & 1.02 & 1.02 & 0.49 \\
\hline$z_{5}$ & 0.06 & 0.52 & 0.52 & 0.3 \\
\hline$z_{6}$ & 0.06 & 0.31 & 0.31 & 0.07 \\
\hline$z_{7}$ & 0.06 & 0.57 & 0.57 & 0.06 \\
\hline
\end{tabular}

TABLE 2: Main material properties of the soil foundation and backfilled soil.

\begin{tabular}{lcc}
\hline Definition & Soft foundation & Backfilled soil \\
\hline Mass density $\left(\mathrm{kg} / \mathrm{m}^{3}\right)$ & 1900 & 1900 \\
Poisson's ratio & 0.3 & 0.3 \\
Initial void ratio & 0.837 & 0.837 \\
Virgin compression index & 0.0853 & 0.082 \\
Unloading-reloading index & 0.00714 & 0.00697 \\
Permeability coefficient & 0.776 & 0.003 \\
Critical-state parameter & 0.933 & 1.502 \\
Preconsolidation pressure $(\mathrm{KPa})$ & 450.587 & 191.361 \\
\hline
\end{tabular}

optimal solution. The optimum volume of the lock head was $2989.30 \mathrm{~m}^{3}$. When the population sizes were 10,20 , and 30 , the population sizes were too small to find the optimum solution. When the population sizes were 40 and 50 , the PSO-EWOA-DE converged at the $13^{\text {th }}$ and $11^{\text {th }}$ iteration, respectively. The number of numerical simulations of the latter was 30 runs more than that of the former. As shown in Figure 12(b), when the population sizes were 40 and 50, the EWOA converged at the $19^{\text {th }}$ and $18^{\text {th }}$ iteration, respectively. The number of numerical simulations of the latter was 140 runs more than that of the former. It could be concluded that population size 40 was more suitable for optimizing the lock head.

6.3. Analysis of Stresses. Figure 13 identifies four feature points $A, B, C$, and $D$, located at the side bottom plate, corridor layer, empty-box layer, and middle bottom plate. These four points were used to analyse the lock head's stress fields and displacement fields at different construction steps. Meanwhile, stress and vertical displacement changes of the lock head before and after optimization were also analysed.

It can be found from Figure 14 that the maximum principle stresses of the ship lock head were significantly affected by the temperature load at early ages. When the concrete was poured, due to the heat released by cement hydration, the tensile stresses increased rapidly with the increase of elastic modulus. The rise in the corridor layer's tensile stress reached $0.33 \mathrm{MPa}$ at early age, which was the largest. It can also be found from Figure 14 that when backfilling the soil, under the influence of the backfilling soil's gravity and the soil foundation's pore water pressure, the tensile stresses of the lock head suddenly increased. The increase of the side bottom plate's tensile stress reached 
TABLE 3: Ship lock construction process.

\begin{tabular}{lccc}
\hline Construction sequence & Construction process & Construction duration (day) & Construction intermissions (day) \\
\hline C1 & Pouring bottom plate & 2 & 8 \\
C2 & Removing bottom plate formwork & 1 & 35 \\
C3 & Backfilling the first layer of soil & 20 & 96 \\
C4 & Pouring the corridor layer & 1 & 10 \\
C5 & Removing corridor layer formwork & 1 & 25 \\
C6 & Backfilling the second layer of soil & 19 & 26 \\
C7 & Pouring the empty-box layer & 1 & 9 \\
C8 & Removing empty-box layer formwork & 1 & 53 \\
C9 & Pouring the second-stage concrete & 1 & 8 \\
C10 & Removing the second-stage concrete formwork & 1 & 20 \\
C11 & Backfilling the third layer of soil & 18 & 30 \\
\hline
\end{tabular}

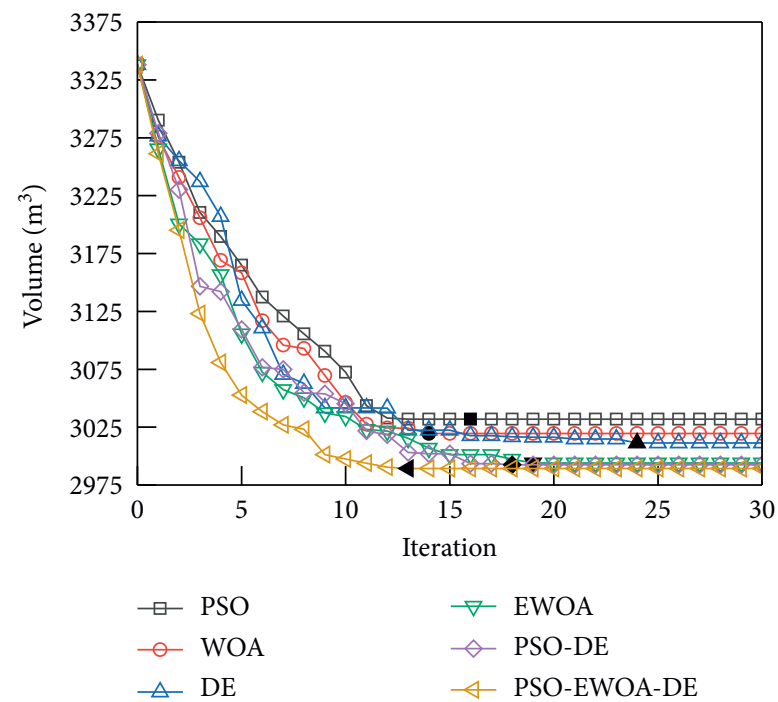

FIGURE 10: Evolutionary processes of PSO, WOA, and EWOA algorithms.

TABle 4: Results of optimization.

\begin{tabular}{lcccccc}
\hline Volume $\left(\mathrm{m}^{3}\right)$ & PSO & WOA & DE & EWOA & PSO-DE & PSO-EWOA-DE \\
\hline Initial design & 3338.04 & 3338.04 & 3338.04 & 3338.04 & 3338.04 & 3338.04 \\
Optimal design & 3031.81 & 3019.49 & 3011.39 & 2994.07 & 2992.55 & 2989.30 \\
Decreasing ratio & $9.17 \%$ & $9.54 \%$ & $9.79 \%$ & $10.30 \%$ & $10.35 \%$ & $10.45 \%$ \\
\hline
\end{tabular}

2.27 MPa, which was the largest. It was concluded that the ship lock head should be protected against cracking when pouring the concrete and backfilling the soil.

Figure 14(a) shows the maximum principle stress change of feature point $A$ on the side bottom plate before and after optimization. When backfilling the soil, the optimal design's side bottom plate's tensile stress became more extensive due to reducing the corridor layer's volume. The maximum increase value was $0.42 \mathrm{MPa}$ when backfilling the third layer of soil. Figure 14(b) shows that the optimal design corridor layer's tensile stress was reduced by $0.21 \mathrm{MPa}$ at early age. The thinning of the corridor layer's coverslip increased the heat dissipation rate and reduced the thermal creep stress. As shown in Figure 14(c), due to the increase in the empty-box layer's volume, the tensile stress of the optimal design's empty-box layer increased by $0.14 \mathrm{MPa}$ at early age.
However, the tensile stress was reduced by $0.17 \mathrm{MPa}$ when backfilling the soil. As shown in Figure 14(d), structural optimization had little effect on the middle bottom plate's stress field. It was concluded that the structural optimization method that comprehensively considered the concrete creep and soft soil consolidation could reflect the time-varying characteristics of the lock head's stress field.

6.4. Displacement Fields' Analysis. The selected feature points' time-history curves of the vertical displacements before and after optimization are shown in Figure 15. It can be found from Figure 15 that the lock head settled instantaneously when pouring the concrete. Subsequently, as the soft foundation's pore water pressure dissipated, the lock head's vertical displacements changed slowly. Since the side 


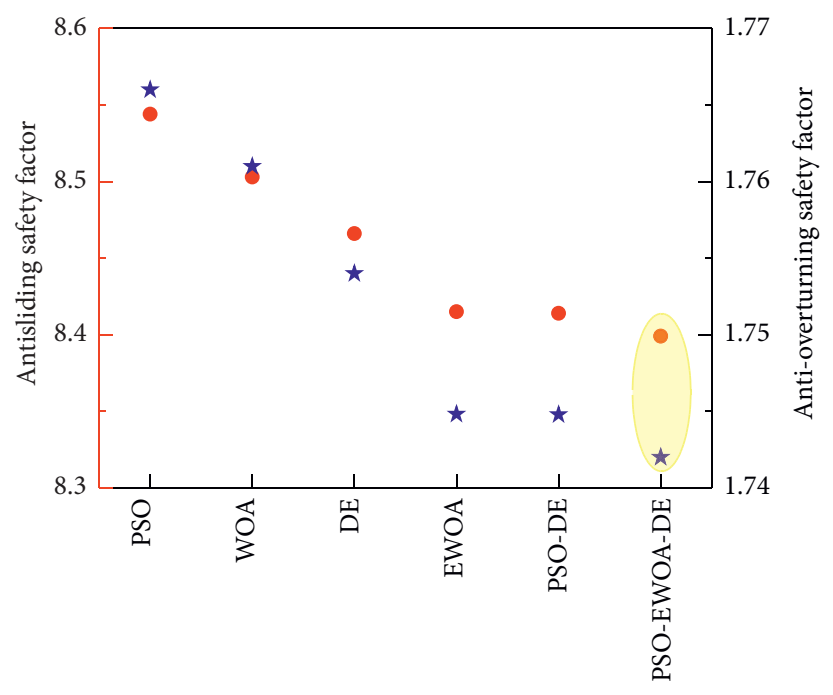

- Antisliding safety factor

$\star$ Anti-overturning safety factor

FIGURE 11: Comparisons of antisliding safety factors and anti-overturning safety factors.

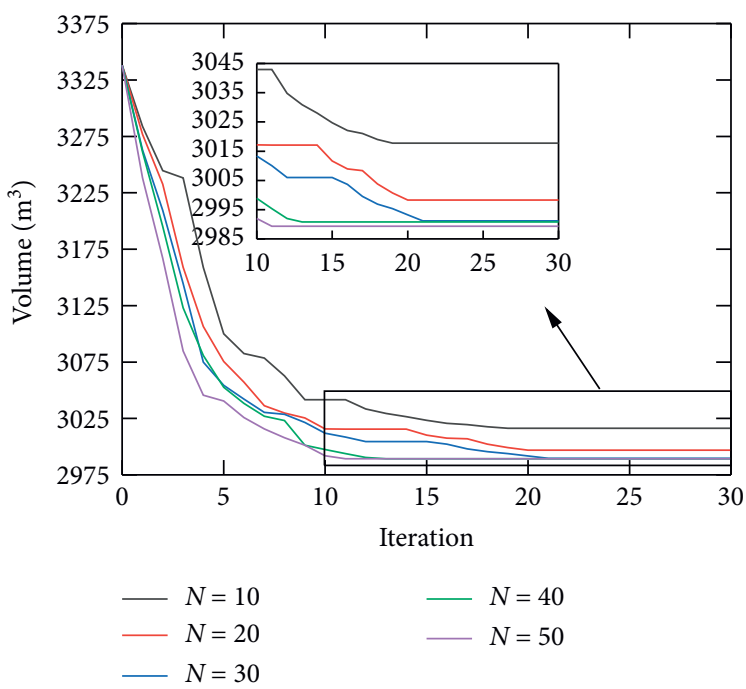

(a)

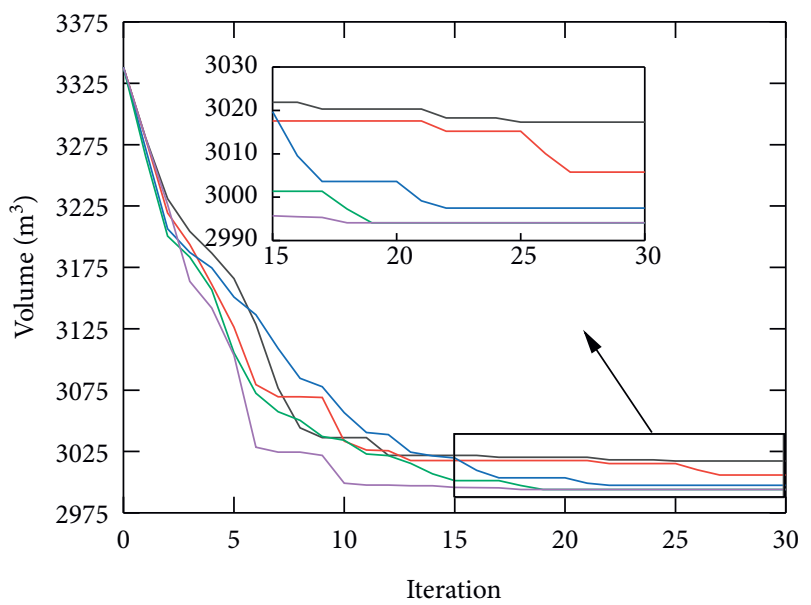

$\begin{aligned} N & =10 \\ N & =20 \\ N & =30\end{aligned}$

$-N=40$

$-N=50$

(b)

FIGURE 12: Effects of population size $N$ on the (a) PSO-EWOA-DE's convergence history and (b) EWOA's convergence history.

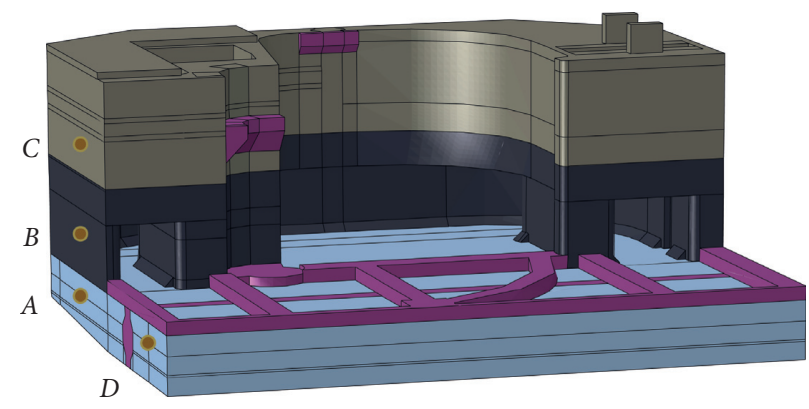

FIGURE 13: Locations of four feature points. 


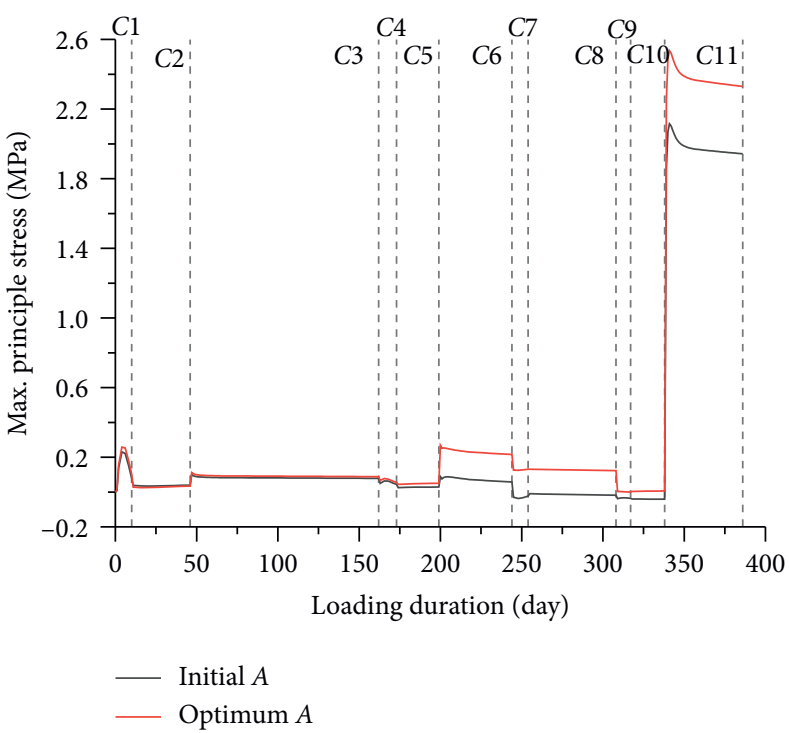

(a)

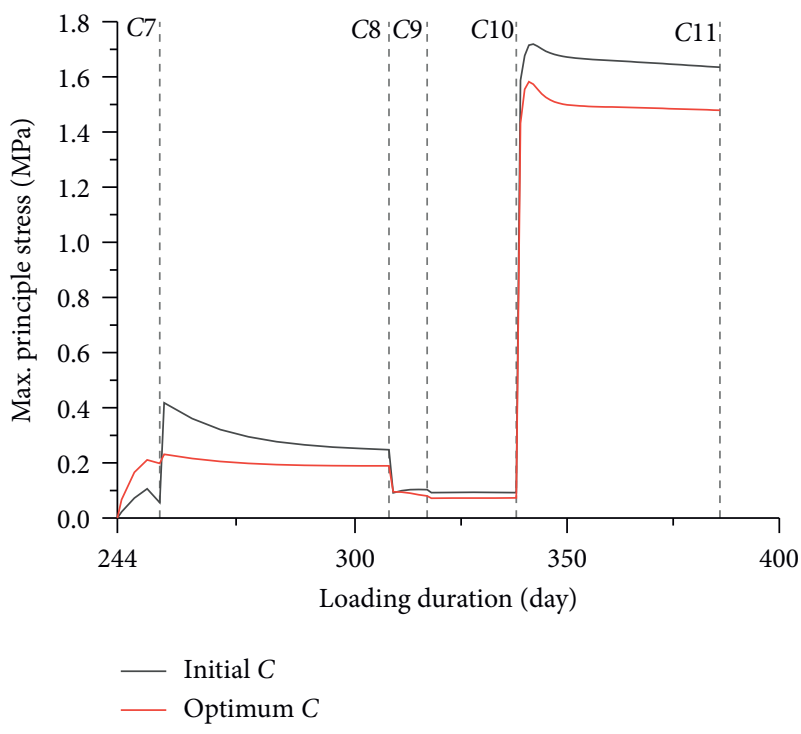

(c)

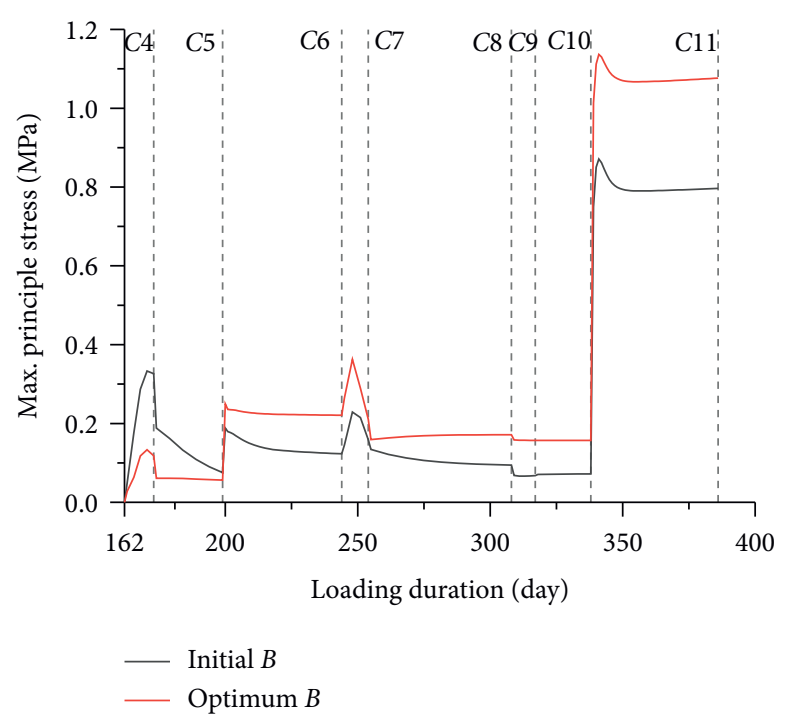

(b)

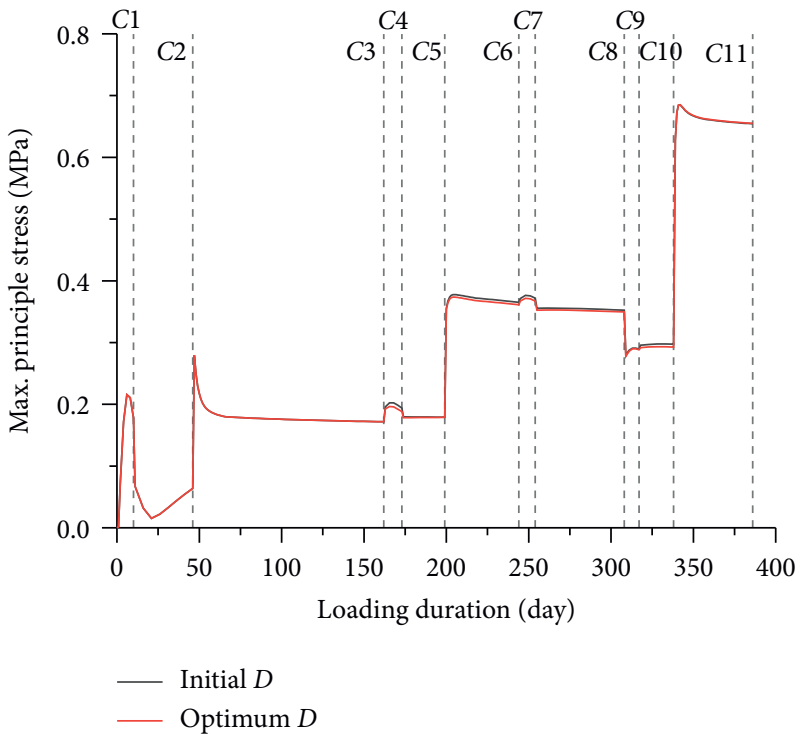

(d)

FIGURE 14: Comparisons of maximum (max.) principle stress before and after optimization at (a) point $A$, (b) point $B$, (c) point $C$, and (d) point $D$.

bottom plate has the largest volume among the five components that consisted of the lock head, the maximum settlement occurred at the side bottom plate, reaching $320 \mathrm{~mm}$. After pouring the bottom plate, the side bottom plate and the middle bottom plate's vertical displacements rebounded due to the exothermic expansion caused by a large amount of concrete hydration. The vertical rebound displacement at the side bottom plate reached $21 \mathrm{~mm}$. It was concluded that the analysis method that comprehensively considered the concrete creep and soft soil consolidation could reflect the time-varying characteristics of the lock head's displacement field.

Figure 15(a) shows the vertical displacement change of feature point $A$ on the side bottom plate before and after optimization. It could be found that the settlement of the optimal design's side bottom plate became smaller due to reducing the volume of the corridor layer. The settlement of the side bottom plate was reduced by $11 \mathrm{~mm}$. Figure 15(b) shows that the optimal design corridor layer's settlement was reduced by $11 \mathrm{~mm}$ due to the lock head's size changes. As shown in Figure 15(c), due to the increase in the empty-box layer's volume, the optimal design's empty-box layer's settlement was increased by $4 \mathrm{~mm}$. As shown in Figure 15(d), the optimal design's middle bottom plate's settlement was decreased by $9 \mathrm{~mm}$. In general, structural optimization could noticeably reduce the lock head's settlement, which was beneficial to engineering safety. 

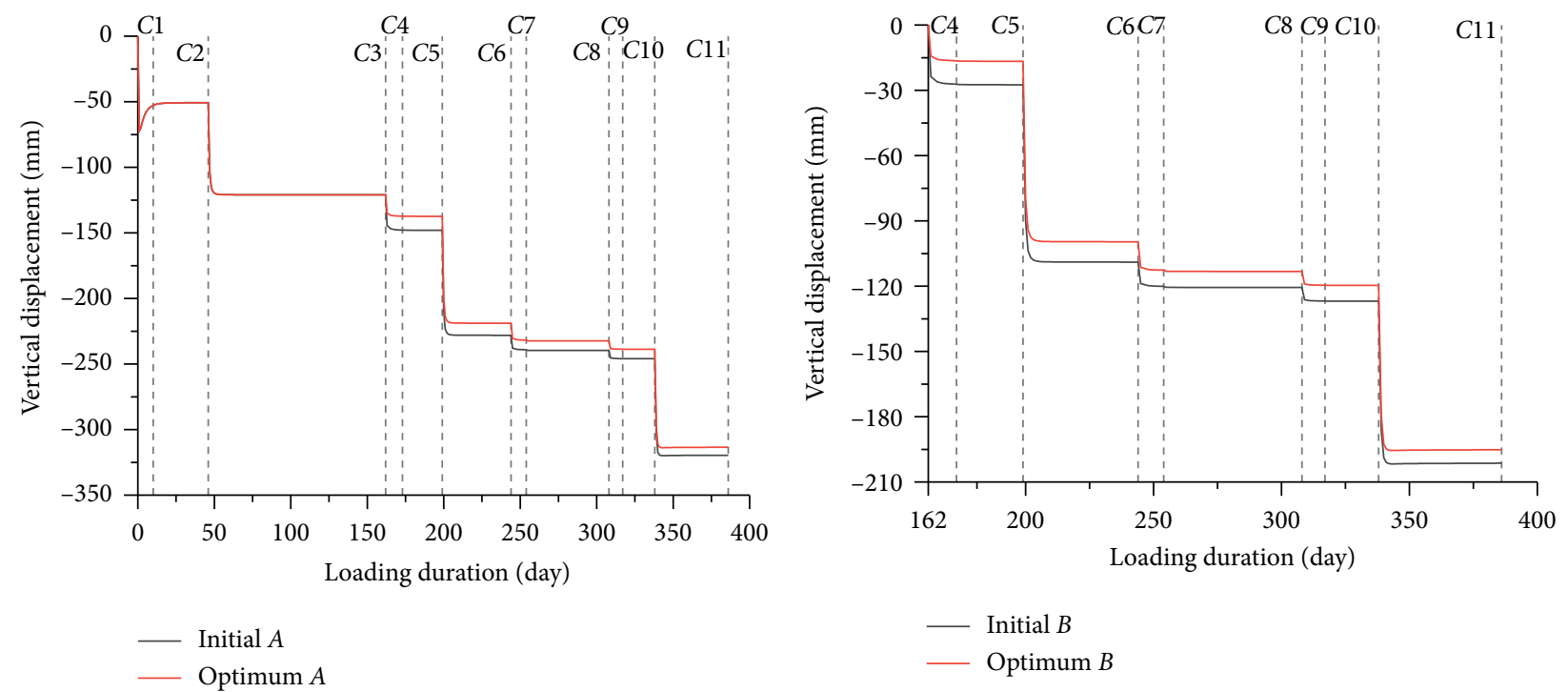

(a)

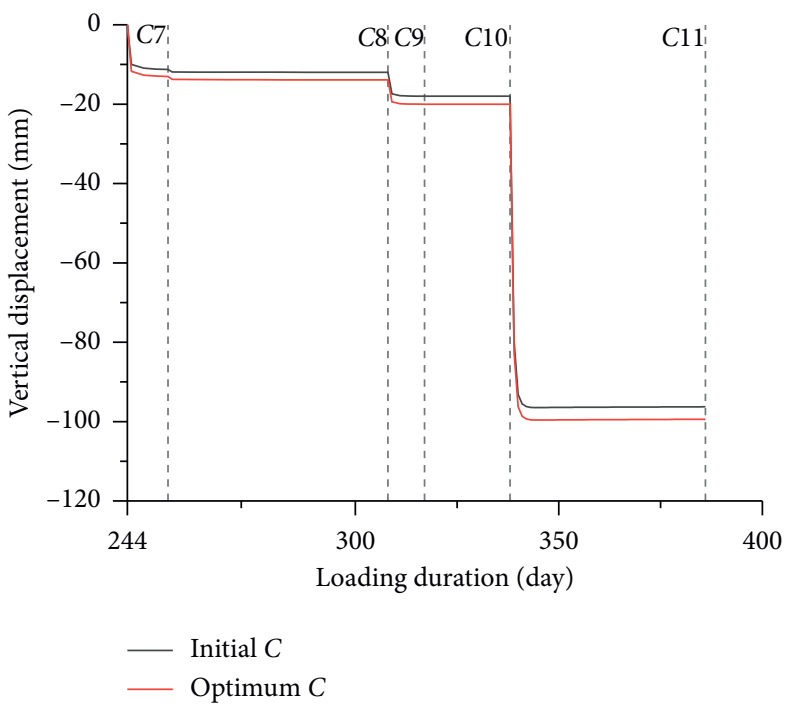

(c)

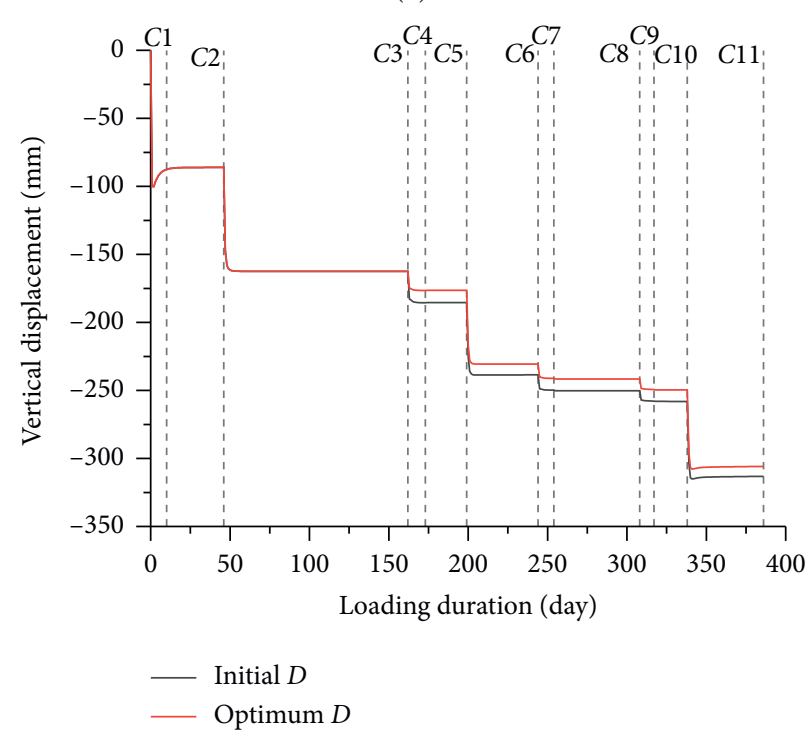

(d)

FIgURE 15: Comparisons of vertical displacements before and after optimization at (a) point $A$, (b) point $B$, (c) point $C$, and (d) point $D$.

\section{Conclusions}

The structural optimization procedure for ship lock heads on soft soil, considering the time-varying effects of the structure and foundation, was established in this paper. By comprehensively considering the linear viscoelastic creep of concrete and the elastoplastic consolidation characteristic of soft soil, a perfect time-dependent analysis method for the lock head on soft soil was proposed. The MCC model was applied in the consolidation calculation of the soft foundation. To obtain the minimum volume, the PSO-EWOA-DE algorithm was proposed to optimize thirty-four design variables of a lock head. Among all the compared algorithms, the PSO-EWOA-DE algorithm showed promising results and had a faster convergence rate. The following conclusions are drawn by analysing the maximum principle stresses and vertical displacements of the lock head:
(1) The temperature load and the backfilling soil's gravity are the main reasons for increasing the ship lock head's tensile stress on the soft foundation. The lock head should be protected against cracking when pouring the concrete and backfilling the soil.

(2) The lock head settled instantaneously when pouring the concrete. Subsequently, as the soft foundation's pore water pressure dissipated, the lock head's vertical displacements changed slowly. The maximum settlement occurred at the side bottom plate.

(3) In general, structural optimization could noticeably reduce the lock head's settlement during construction, which was beneficial to engineering safety. The analysis method that comprehensively considered the concrete creep and soft soil consolidation could 
reflect the lock head's stress field and displacement field's time-varying characteristics.

This structural optimization method of the ship lock head considered the time-varying effects of the structure and foundation. Future work should consider the optimization of the ship lock head's construction sequence.

\section{Data Availability}

The data used to support the findings of this study are included within the article.

\section{Conflicts of Interest}

The authors declare that there are no conflicts of interest regarding the publication of this paper.

\section{Acknowledgments}

This work was supported by the National Natural Science Foundation of China (no. 51579089).

\section{References}

[1] H. Li, Q. Tian, H. Zhao, A. Lu, and J. Liu, "Temperature sensitivity of $\mathrm{MgO}$ expansive agent and its application in temperature crack mitigation in shiplock mass concrete," Construction and Building Materials, vol. 170, pp. 613-618, 2018.

[2] C. B. Farnsworth, S. F. Bartlett, D. Negussey, and A. W. Stuedlein, "Rapid construction and settlement behavior of embankment systems on soft foundation soils," Journal of Geotechnical and Geoenvironmental Engineering, vol. 134, no. 3, pp. 289-301, 2008.

[3] C. Su, Y. Wu, and Y. Su, "Optimal design of miter gate lock head with gradient corridor in flow direction," Port \& Waterway Engineering (Chinese Journal), vol. 496, no. 10, pp. 134-138, 2014.

[4] C. Su and J. W. Bai, "Structural optimization of ship lock heads during construction period considering concrete creep," Mathematical Problems in Engineering, vol. 2020, Article ID 5495202, , 2020.

[5] R. I. Perez and K. Behdinan, "Particle swarm approach for structural design optimization," Computers \& Structures, vol. 85, no. 19-20, pp. 1579-1588, 2007.

[6] X. M. Hu and J. Zhang, "Minimum cost multicast routing using ant colony optimization algorithm," Mathematical Problems in Engineering, vol. 2013, Article ID 432686, , 2013.

[7] Y. Zhang, S. Wang, and G. Ji, "A comprehensive survey on particle swarm optimization algorithm and its applications," Mathematical Problems in Engineering, vol. 2015, Article ID 931256, , 2015.

[8] M. Varadarajan and K. S. Swarup, "Differential evolutionary algorithm for optimal reactive power dispatch," International Journal of Electrical Power \& Energy Systems, vol. 30, no. 8, pp. 435-441, 2008.

[9] H. Gao, S. Kwong, J. Yang, and J. Cao, "Particle swarm optimization based on intermediate disturbance strategy algorithm and its application in multi-threshold image segmentation," Information Sciences, vol. 250, pp. 82-112, 2013.
[10] J. Kennedy and R. Eberhart, "Particle swarm optimization," in Proceedings of the 1995 IEEE International Conference on Neural Networks, pp. 1942-1948, Perth, Australia, December 1995.

[11] P. C. Fourie and A. A. Groenwold, "The particle swarm optimization algorithm in size and shape optimization," Structural and Multidisciplinary Optimization, vol. 23, no. 4, pp. 259-267, 2002.

[12] L. J. Li, Z. B. Huang, and F. Liu, "A heuristic particle swarm optimization method for truss structures with discrete variables," Computers \& Structures, vol. 87, no. 7-8, pp. 435-443, 2009.

[13] P. C. Fourie and A. A. Groenwold, "Particle swarms in topology optimization," in Proceedings of the Fourth World Congress of Structural and Multidisciplinary Optimization, pp. 1771-1776, Dalian, China, May 2001.

[14] G. Venter and J. Sobieszczanski-Sobieski, "Multidisciplinary optimization of a transport aircraft wing using particle swarm optimization," Structural Multidisciplinary Optimization, vol. 26, no. 1-2, pp. 121-131, 2004.

[15] S. Mirjalili and A. Lewis, "The whale optimization algorithm," Advances in Engineering Software, vol. 95, pp. 51-67, 2016.

[16] D. Oliva, M. Ella Hassanien, and A. E. Hassanien, "Parameter estimation of photovoltaic cells using an improved chaotic whale optimization algorithm," Applied Energy, vol. 200, pp. 141-154, 2017.

[17] I. Aljarah, H. Faris, and S. Mirjalili, "Optimizing connection weights in neural networks using the whale optimization algorithm," Soft Computing, vol. 22, no. 1, pp. 1-15, 2018.

[18] Q. Fan, Z. Chen, W. Zhang et al., "ESSAWOA: enhanced whale optimization algorithm integrated with salp swarm algorithm for global optimization," Engineering with Computers, vol. 111, pp. 1-18, 2020.

[19] G. Kaur and S. Arora, "Chaotic whale optimization algorithm," Journal of Computational Design and Engineering, vol. 5, no. 3, pp. 275-284, 2018.

[20] P. D. P. Reddy, V. C. V. Reddy, and T. G. Manohar, "Whale optimization algorithm for optimal sizing of renewable resources for loss reduction in distribution systems," Renewables: Wind, Water, and Solar, vol. 4, no. 1, pp. 1-13, 2017.

[21] M. M. Mafarja and S. Mirjalili, "Hybrid whale optimization algorithm with simulated annealing for feature selection," Neurocomputing, vol. 260, pp. 302-312, 2017.

[22] A. N. Jadhav and N. Gomathi, "WGC: hybridization of exponential grey wolf optimizer with whale optimization for data clustering," Alexandria Engineering Journal, vol. 57, no. 3, pp. 1569-1584, 2018.

[23] A. Kaveh and M. I. Ghazaan, "Enhanced whale optimization algorithm for sizing optimization of skeletal structures," Mechanics Based Design of Structures and Machines, vol. 45, no. 3, pp. 345-362, 2017.

[24] M. H. Qais, H. M. Hasanien, and S. Alghuwainem, "Enhanced whale optimization algorithm for maximum power point tracking of variable-speed wind generators," Applied Soft Computing, vol. 86, Article ID 105937, 2020.

[25] R. Storn and K. Price, “"Differential evolution-a simple and efficient heuristic for global optimization over continuous spaces," Journal of Global Optimization, vol. 11, no. 4, pp. 341-359, 1997.

[26] Z. Wang, Y. Li, and Y. Tang, "An efficient hybrid DE-WOA algorithm for numerical function optimization," in Proceedings of the 2019 IEEE 28th International Symposium on Industrial Electronics (ISIE), pp. 2629-2634, Vancouver, Canada, June 2019. 
[27] N. Noman and H. Iba, "Differential evolution for economic load dispatch problems," Electric Power Systems Research, vol. 78, no. 8, pp. 1322-1331, 2008.

[28] M. Zhou, Y. Zhang, and S. Jin, "Dynamic optimization of heated oil pipeline operation using PSO-DE algorithm," Measurement, vol. 59, pp. 344-351, 2015.

[29] Z. P. Bažant, "Prediction of concrete creep and shrinkage: past, present and future," Nuclear Engineering and Design, vol. 203, no. 1, pp. 27-38, 2001.

[30] G. De Schutter and L. Taerwe, "Fictitious degree of hydration method for the basic creep of early age concrete," Materials and Structures, vol. 33, no. 6, pp. 370-380, 2000.

[31] Z. P. Bažant and J.-K. Kim, "Improved prediction model for time-dependent deformations of concrete: Part 2-basic creep," Materials and Structures, vol. 24, no. 6, pp. 409-421, 1991.

[32] R. Goel, R. Kumar, and D. K. Paul, "Comparative study of various creep and shrinkage prediction models for concrete," Journal of Materials in Civil Engineering, vol. 19, no. 3, pp. 249-260, 2007.

[33] J. J. Brooks, "30-year creep and shrinkage of concrete," Magazine of Concrete Research, vol. 57, no. 9, pp. 545-556, 2005.

[34] M. H. Hubler, R. Wendner, and Z. P. Bažant, "Comprehensive database for concrete creep and shrinkage: analysis and recommendations for testing and recording," ACI Materials Journal, vol. 112, no. 4, pp. 547-558, 2015.

[35] N. J. Gardner and M. J. Lockman, "Design provisions for drying shrinkage and creep of normal-strength concrete," ACI Materials Journal, vol. 98, no. 2, pp. 159-167, 2001.

[36] Z. P. Bažant and L. Panula, "Practical prediction of timedependent deformations of concrete," Matériaux et Construction, vol. 11, no. 5, pp. 317-328, 1978.

[37] ACI Committe 209, "Guide for modeling and calculating shrinkage and creep in hardened concrete," American Concrete Institute, Indianapolis IN, USA, 2008.

[38] Z. P. Bažant and Y. Xi, "Continuous retardation spectrum for solidification theory of concrete creep," Journal of Engineering Mechanics, vol. 121, no. 2, pp. 281-288, 1995.

[39] B. Zhu, Thermal Stresses and Temperature Control of Mass Concrete, Butterworth-Heinemann, Amsterdam, Netherlands, 2013.

[40] J. Wang and A. L. Liu, "Application of ABAQUS to calculation of creep thermal stress of mass concrete," Journal of Hohai University (Natural Sciences), vol. 36, no. 4, pp. 532-537, 2008.

[41] J. C. Small, J. R. Booker, and E. H. Davis, "Elasto-plastic consolidation of soil," International Journal of Solids and Structures, vol. 12, no. 6, pp. 431-448, 1976.

[42] K. Terzaghi, Erdbaumechanik Auf Bodenphysikalischer Grundlage, Franz Deuticke, Vienna, Austria, 1925.

[43] M. A. Biot, "General theory of three dimensional consolidation," Journal of Applied Physics, vol. 12, no. 2, pp. 155-164, 1941.

[44] R. S. Sandhu and E. L. Wilson, "Finite-element analysis of seepage in elastic media," Journal of the Engineering $\mathrm{Me}$ chanics Division, vol. 95, no. 3, pp. 641-652, 1969.

[45] D. Sheng, S. W. Sloan, and H. S. Yu, "Aspects of finite element implementation of critical state models," Computational Mechanics, vol. 26, no. 2, pp. 185-196, 2000.

[46] K. A. Mita, G. R. Dasari, and K. W. Lo, "Performance of a three-dimensional hvorslev-modified Cam clay model for overconsolidated clay," International Journal of Geomechanics, vol. 4, no. 4, pp. 296-309, 2004.
[47] S. K. Jain, Analysis of the pressuremeter test by FEM formulation of the elasto-plastic consolidation, Ph.D. Thesis, Virginia Polytechnic Institute and State University, Blacksburg, VA, USA, 1985.

[48] C. Xu and C. Su, "Development of an effective method for calculations related to creep," Arabian Journal for Science and Engineering, vol. 43, no. 4, pp. 1561-1571, 2018.

[49] T. Luo, Y. P. Yao, and W. Hou, Soil Constitutive Models, China Communications Press, Beijing, China, 2010.

[50] J. Zhang, L. Lin, and D. A. Sun, "Similarity solution for undrained cylindrical cavity contraction in anisotropic modified Cam-clay model soils," Computers and Geotechnics, vol. 120, Article ID 103405, 2020.

[51] R. I. Borja and S. R. Lee, "Cam-clay plasticity, part 1: implicit integration of elasto-plastic constitutive relations," Computer Methods in Applied Mechanics and Engineering, vol. 78, no. 1, pp. 49-72, 1990.

[52] T. Matsui and N. Abe, "Multi-dimensional elasto-plastic consolidation analysis by finite element method," Soils and Foundations, vol. 21, no. 1, pp. 79-95, 1981.

[53] J. P. Carter, J. R. Booker, and J. C. Small, "The analysis of finite elasto-plastic consolidation," International Journal for $\mathrm{Nu}$ merical and Analytical Methods in Geomechanics, vol. 3, no. 2, pp. 107-129, 1979.

[54] S. W. Sloan and A. J. Abbo, "Biot consolidation analysis with automatic time stepping and error control Part 1: theory and implementation," International Journal for Numerical and Analytical Methods in Geomechanics, vol. 23, no. 6, pp. 467-492, 1999.

[55] R. Poli, J. Kennedy, and T. Blackwell, "Particle swarm optimization," Swarm Intelligence, vol. 1, no. 1, pp. 33-57, 2007.

[56] C.-Y. Wu and K.-Y. Tseng, "Truss structure optimization using adaptive multi-population differential evolution," Structural and Multidisciplinary Optimization, vol. 42, no. 4, pp. 575-590, 2010.

[57] S. Talatahari, M. Kheirollahi, C. Farahmandpour, and A. H. Gandomi, "A multi-stage particle swarm for optimum design of truss structures," Neural Computing and Applications, vol. 23, no. 5, pp. 1297-1309, 2013. 